Published in final edited form as:

ACS Appl Mater Interfaces. 2019 October 23; 11(42): 38405-38416. doi:10.1021/acsami.9b11783.

\title{
A New Formyl Peptide Receptor-1 Antagonist Conjugated Fullerene Nanoparticle for Targeted Treatment of Degenerative Disc Diseases
}

\author{
$\mathrm{Li} \mathrm{Xiao}^{\dagger, \#}$, Rong Huang${ }^{\S, \#}$, Yi Zhang", Tinghui Li ${ }^{\S}$, Jun Dai ${ }^{\dagger}$, Naga Nannapuneni ${ }^{\dagger}$, Timothy \\ R. Chastanet ${ }^{\dagger}$, Matthew Chen ${ }^{\dagger}$, Francis H. Shen ${ }^{\dagger}$, Li Jin ${ }^{\dagger}$, Harry C. Dorn ${ }^{*}, \S^{\prime},{ }^{\perp}$ Xudong Li $^{*}, \dagger, \ddagger$ \\ tDepartment of Orthopaedic Surgery and University of Virginia, Charlottesville, Virginia 22908, \\ United States
}

¥Department of Biomedical Engineering, University of Virginia, Charlottesville, Virginia 22908, United States

§Department of Chemistry, Virginia Polytechnic Institute and State University, Blacksburg, Virginia 24061 United States

"Biomedical Imaging Research Institute, Cedars-Sinai Medical Center, Los Angeles, California 90048, United States

${ }^{\perp}$ Fralin Biomedical Research Institute, Roanoke, Virginia 24016, United States

\begin{abstract}
Intervertebral disc degeneration associated back pain is the most common cause of disability worldwide; however, no safe and effective treatments have been available. Here, we report a new functionalized nanofullerene conjugated with a peptide that binds specifically to a formyl peptide receptor-1 (FPR-1) expressed on activated macrophages. The new nanoparticle (aka FT- $\mathrm{C}_{60}$ ) was synthesized by conjugating carboxyl- $\mathrm{C}_{60}$ with the primary amine group of the peptide with a fluorescence dye for easy detection. The new nanoparticle was characterized by X-ray photoelectron spectroscopy, mass spectroscopy, and gel electrophoresis. It possessed effective
\end{abstract}

*Corresponding Authors hdorn@vt.edu. Tel: 540-526-2049 (H.C.D.), x12n@ virginia.edu. Tel: 1-434-924-5937. Fax: 1-434-924-1691

(X.L.).

Author Contributions

${ }^{\#}$ L.X. and R.H. contributed equally to this manuscript.

The authors declare no competing financial interest.

ASSOCIATED CONTENT

Supporting Information

The Supporting Information is available free of charge on the ACS Publications website at DOI: 10.1021/acsami.9b11783. Detailed materials and reagents, synthesis and characterization of targeting peptides (Scheme S1, Figures S1, S2), intermediate synthesis of functionalized $\mathrm{C}_{60}$ (Scheme $\mathrm{S} 2$ ). Characterization of the functionalized $\mathrm{C}_{60}$ and the peptide- $\mathrm{C}_{60}$ conjugate FT- $\mathrm{C}_{60}$ including XPS multiplex, MALDO-TOF-MS, ${ }^{1} \mathrm{H}$ NMR, gel electrophoresis, UV-vis spectroscopy, and partition coefficient (Figures S3-S7). Cell culture and immunofluorescence staining of FPR-1 in macrophage cells (Figure S8). Macrophage cell morphology under dose-dependent treatment of FT-C 60 (Figure S9). Time-dependent LPS stimulation of proinflammatory genes (Figure S10). Real-time RT-PCR of pro-inflammatory genes normalized by $18 \mathrm{~S}$ (Figure S11). Unchanged proinflammatory gene profile of macrophages with peptide 1 treatment by real-time RT-PCR (Figure S12). Additional ex vivo NIRF imaging of lumbar spine (Figure S13) and representative organ distribution images (Figure S14). Additional histological images (Figure S15) and customized method for histological quantification (Figure S16). Primer sequences of real-time RT-PCR experiments (Table S1) (PDF) A mouse treadmill video of pain behavior on POD 6 showing in vivo efficacy of systemic delivery of FT-C 60 (MP4) 
radical (hydroxyl and superoxide anions) scavenging capabilities in electron paramagnetic resonance spectroscopy. In cultured cells, the nanoparticle FT- $\mathrm{C}_{60}$ demonstrated preferential binding to FPR-1 on activated macrophages and significantly attenuated mRNA expressions of proinflammatory factors including interleukin-6, interleukin-1, tumor necrosis factor-alpha, and cyclooxygenase-2. In vivo animal studies exhibited that a single intravenous injection of FT- $\mathrm{C}_{60}$ effectively alleviated pain in an established mouse model of radiculopathy for up to post-operation day (POD) 12. Ex vivo near-infrared fluorescence imaging of the mouse spine confirmed the targeting property of FT- $\mathrm{C}_{60}$ toward the injured disc on POD 14. Quantitative analysis of histological staining on spine sections showed that nanoparticle $\mathrm{FT}^{-\mathrm{C}_{60}}$ dramatically reduced inflammation at the local injury site compared to injury only on POD 7. In summary, we developed a novel targeted nanoparticle for treatment of lumbar radiculopathy by systemic delivery. This is a first-of-its-kind study for developing a novel class of targeted and systemic nanoparticle therapeutics to treat degenerative disc diseases.

\section{Graphical abstract}

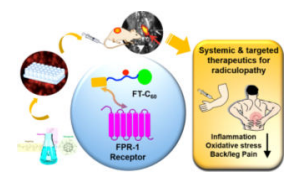

\section{Keywords}

intervertebral disc degeneration; low back pain; targeted therapy; fullerene; formyl peptide receptor-1

\section{INTRODUCTION}

The most recent Global Burden of Disease reported back pain as the most common cause of disability worldwide. ${ }^{1-3}$ Back/leg pain is the most common health problem with a prevalence of over $80 \%$ and an estimated annual cost of $\$ 100$ billion in the United States. ${ }^{3,4}$ Although various factors may contribute to the pathogenesis of back pain, intervertebral disc (IVD) degeneration has been considered as a major cause. ${ }^{5,6}$ Unfortunately, this devastating condition can only be treated with symptomatic relief interventions, as no effective and disease-modifying medications are yet available. ${ }^{7,8}$ Nonsteroidal anti-inflammatory drugs (NSAIDs) such as diclofenac, ibuprofen, and naproxen are the most commonly used medications for low back pain. However, it is a well-known fact that NSAIDs can cause stomach ache and bleeding, limiting their usability. Opioid-based analgesics are somewhat effective in alleviating pain symptoms; however, they do not target the pain source, and opioid overuse may cause severe substance abuse and/or drug tolerance. Epidural steroid injection (ESI) serves as a reasonable treatment to reduce inflammation and numb the pain via inhibition of prostaglandins in the arachidonic acid signaling cascade. However, ESI is only effective in some patients and can potentially lead to serious complications such as infection and hematoma. Therefore, it has become an urgent and unmet medical need to develop a new therapeutic strategy to resolve painful radiculopathy, such as a systemic and targeted therapy that is a safe, simple, and effective way. 
Despite numerous pathogenic factors contributing to the initiation and progression of degenerative disc diseases, inflammation and the dynamic interplay of immune cells play critical roles in disc degeneration and associated low back/leg pain. ${ }^{6,9}$ IVD is the largest avascular organ in the human body and considered as an immune-privileged site. A normal disc is an immune-privileged organ, whereas a herniated disc evokes complex immune responses. The central nucleus pulpous (NP) is particularly isolated from our immune system due to its location between two cartilaginous endplates and inside the dense collagen fibrous structure of the annulus fibrosus (AF).$^{10}$ In addition to such physiological barriers, disc cells actively resist the invasion of immune cells shown by the expression of Fas ligand (FasL), a characteristic of the immune-privileged site. During disc herniation, NP tissue extrudes into epidural space, evoking autoimmune responses, abundant infiltration of immune cells (e.g., macrophages and dendritic cells, T and B cells, etc.), and cytokine production by both disc and immune cells exacerbating the inflammation and pain. ${ }^{5}$ Approximately $66 \%$ of surgically obtained herniated human disc specimens show abundant macrophage infiltration, which suggests that they are a prominent source of inflammation and pain. ${ }^{11-13}$ Our previous study also illustrated abundant macrophage infiltration near the site of disc hernia in a mouse model of disc herniation. ${ }^{14,15}$ All these findings support that activated inflammatory cells such as macrophages at local disc hernia sites might be a valid target for therapeutic development.

Formyl peptide receptor-1 (FPR-1) is highly expressed in leukocytes such as neutrophils, monocytes, and macrophages under an inflammatory insult. It has been extensively reported that circulating monocytes transform into macrophages during the late phase of inflammatory diseases for phagocytic cleanup. In our previous study, we demonstrated that the intravenously administered cFIFIF peptide specifically bound to FPR-1 expressed on activated macrophages/monocytes at the local disc hernia site, ${ }^{14}$ empowering targeted drug delivery to disc hernia sites - the source of pain. Meanwhile, nanoparticle fullerene $\left(\mathrm{C}_{60^{-}}\right.$ $\mathrm{C}_{80}$ ) is composed of $60-80$ carbons in hollow sphere form that is $\sim 1 \mathrm{~nm}$ in diameter. Fullerene and its derivatives have showed promising therapeutic potential in a range of pathological conditions involving oxidative stress and inflammation. ${ }^{16-18}$ Bioactivity examples of fullerene may include antimicrobial activity, neuroprotection, DNA cleavage, apoptosis, ion channel inhibition, and inhibition of amyloid formation. ${ }^{19,20}$ Due to the high degree of unsaturation, the molecule is able to effectively trap free radicals as a radical sponge. Fullerenes are intrinsically superior to growth factors, cytokines, and enzymes because of their long-lasting activity and cell membrane-penetrating ability. We are the first to discover the essential role of nanomedicine in treating degenerative disc diseases. We demonstrated that fullerol (water-soluble form of fullerene) possessed pleiotropic therapeutic functions in the complex pathological context of discogenic back/leg pain by harmonizing pathological cross-talks among the disc, spinal nerve, and immune system via neuroprotective, disc regenerative, anti-inflammatory, and analgesic effects. ${ }^{17,20,21}$

As shown in Figure 1, we aim to develop a new FPR-1 targeted $\mathrm{C}_{60}$ nanoparticle (referred as FT- $\mathrm{C}_{60}$ ) as a promising nanomedicine to alleviate lumbar radiculopathy by intravenous administration. Our FT- $\mathrm{C}_{60}$ has a modular design, including functionalized $\mathrm{C}_{60}$ as the therapeutic moiety, polyethylene glycol (PEG) and lysine (K) as the linker and spacer, and the cFlFIF peptide as the targeting modality, and a near-infrared fluorescence dye Cyanine 5 
(Cy5) to ease detection. This is a first-of-its-kind study for developing a novel class of targeted nanoparticles to treat discogenic pain by systemic delivery and demonstrating its potent anti-inflammatory and pain alleviation effect in a mouse model of lumbar radiculopathy.

\section{RESULTS AND DISCUSSION}

\subsection{Chemical Synthesis and Characterization of Targeting Peptide, Functionalized $\mathrm{C}_{60}$, and $\mathrm{FT}-\mathrm{C}_{60}$ Conjugate.}

Chemical synthesis of fluorescence dye Cy5 labeled peptide sequence [cFlFIFK-PEG $24^{-}$ (Cy5)-K] was performed using established solid-phase peptide chemistry as shown in Figure 2a and was characterized by MALDI-TOF-MS with detected molecular weights of 2837.44 [M-H], $2838.354[\mathrm{M}]$, and 2839.358 [M+H] (Figure S1), which was also confirmed with LC-ESI-MS (Figure S2). In our initial design, two peptide structures (peptide 1 in Figure 2a and peptide $\mathbf{2}$ in Scheme S1) were designed and synthesized with their reactive primary amine at two different positions, respectively.

Functionalized $\mathrm{C}_{60}$ was prepared as in Figure $2 \mathrm{~b}$ with in situ prepared starting material succinic acid acyl peroxide (Scheme S2). According to XPS data, the empirical chemical formula of functionalized $\mathrm{C}_{60}$ was calculated as $\mathrm{C}_{60}(\mathrm{OH})_{21}\left(\mathrm{CH}_{2} \mathrm{CH}_{2} \mathrm{COOH}\right)_{13}$ with an estimated mass of 2026 (Figure S3). The MALDI-TOF mass spectra suggested that the molecular weight of functionalized $\mathrm{C}_{60}$ (Figure S4) was 2387 , corroborating the formula $\mathrm{C}_{60}(\mathrm{OH})_{28}\left(\mathrm{CH}_{2} \mathrm{CH}_{2} \mathrm{COOH}\right)_{16}$ (mass estimated:2364) with a $\mathrm{Na}^{+}([\mathrm{M}+\mathrm{Na}])^{+}$.

Chemical conjugation of peptide and functionalized $\mathrm{C}_{60}$ was attempted in various approaches, including DIC/HOBt, EDC/NHS, and microwave-assisted DIEA/HATU coupling. Conjugation of FT- $\mathrm{C}_{60}$ was successfully achieved with peptide $\mathbf{1}$ and carboxyl- $\mathrm{C}_{60}$ using microwave-assisted DIEA/HATU coupling method (Figure 2c). Functionalized $\mathrm{C}_{60}$ and $\mathrm{FT}-\mathrm{C}_{60}$ were characterized by various techniques, such as UV-vis spectroscopy, mass spectroscopy, XPS, NMR, and gel electrophoresis. The conjugation of peptide $\mathbf{1}$ and functionalized $\mathrm{C}_{60}$ was confirmed by MALDI-TOF-MS (Figures S4 and S5), XPS survey spectra (Figure 3a,b), UV-vis (Figure 3c), ${ }^{1} \mathrm{H}$ NMR (Figure 3d), and native polyacrylamide gel electrophoresis (Figure S6). It is well recognized that peptides and other functional groups are readily cleaved from the $\mathrm{C}_{60}$ structure during ionization by MALDI-TOF-MS. The molecular weight of newly synthesized conjugate FT- $_{60}$ was estimated to be $\sim 5200$, which possibly suggested a 1:1 ratio of peptide-to- $\mathrm{C}_{60}$ conjugation by MALDI-TOF-MS (see the Supporting Information). As shown in the survey spectra of the functionalized $\mathrm{C}_{60}$ and FT- $\mathrm{C}_{60}$ conjugate in Figure 3a,b, the peaks centered at binding energies of 284.4, 400.4, 497.4, and $533.4 \mathrm{eV}$ represent $\mathrm{C}_{1 \mathrm{~s}}, \mathrm{~N}_{1 \mathrm{~s}}, \mathrm{Na}$ Auger, and $\mathrm{O}_{1 \mathrm{~s}}$, respectively. The appearance of the peak intensity for $\mathrm{N}_{1 \mathrm{~s}}$ for the FT- $\mathrm{C}_{60}$ conjugate was readily observed after chemical conjugation in comparison with the functionalized $\mathrm{C}_{60}$ alone. This clearly suggests the successful conjugation of the peptide in the final FT- $_{60}$ conjugate. Based on the peak intensities of $\mathrm{N}_{1 \mathrm{~s}}$ and $\mathrm{C}_{1 \mathrm{~s}}$, the XPS data suggested that the peptide-to-functionalized $\mathrm{C}_{60}$ ratio was estimated to be 1.6:1, which was consistent with a similar value from the ${ }^{1} \mathrm{H}$ NMR data vide infra. In addition, the UV-vis absorbance spectrum also revealed that the $\mathrm{FT}_{-} \mathrm{C}_{60}$ conjugate exhibited the characteristics of both the peptide and functionalized $\mathrm{C}_{60}$ with a 
unique absorbance centered at $650 \mathrm{~nm}$, indicating the presence of Cy5 and substantiating the successful conjugation (Figure 3c). As shown in Figure 3d, the ${ }^{1} \mathrm{H}$ NMR spectra of both FT$\mathrm{C}_{60}$ conjugate and functionalized $\mathrm{C}_{60}$ exhibited the methylene hydrogens that were adjacent to the carboxyl group on the $\mathrm{C}_{60}$ cage at $\sim 2.55 \mathrm{ppm}$. In addition, the ${ }^{1} \mathrm{H}$ NMR spectrum of the $\mathrm{FT}_{-} \mathrm{C}_{60}$ conjugate also exhibited a broad $\mathrm{PEG}^{1} \mathrm{H}$ peak centered at $3.5 \mathrm{ppm}$, which again suggested the successful conjugation of the peptide to the fullerene $\mathrm{C}_{60}$ cage. Integration of the PEG versus methylene hydrogens in the ${ }^{1} \mathrm{H}$ NMR spectrum suggested a peptide-to- $\mathrm{C}_{60}$ ratio of 1.5:1, consistent with the XPS data vide supra (see the Supporting Information for detailed ${ }^{1} \mathrm{H}$ NMR data).

Since hydrophilicity/ hydrophobicity plays a critical role for biocompatibility and PK/PD profiles, the partition coefficient $(\log P)$ of the conjugate $\mathrm{FT}_{-} \mathrm{C}_{60}$ was assessed. After conjugation, the hydrophilicity of FT- $\mathrm{C}_{60}(\log P,-1.25 \pm 0.13)$ increased compared to the targeting moiety peptide $1(\log P,-0.84 \pm 0.13)$, which was suitable for downstream biological applications (Figure S7). It is noteworthy that the $\log P$ value was directly affected by structural modification, which would in turn affect the bioavailability and downstream biological evaluations.

\subsection{Newly Synthesized FT- $\mathrm{C}_{60}$ Possessed Strong Radical Scavenging Capability.}

The electron paramagnetic resonance (EPR) technique was used to evaluate the scavenging capability of the functionalized $\mathrm{C}_{60}$ and the conjugate FT- $\mathrm{C}_{60}$ to eliminate ${ }^{\circ} \mathrm{OH}$ and $\mathrm{O}_{2}{ }^{-}$in a cell free system. ${ }^{17}$ Both radicals are among the most common reactive oxygen species (ROS) in the biological system with profound effects in inducing oxidative stress and proinflammatory responses. As shown in Figure 4a, the EPR assay was based on the competition between 5-diethoxyphosphoryl-5-methyl-1-pyrroline $N$-oxide (DEPMPO) and the functionalized carboxyl- $\mathrm{C}_{60}$ or the conjugate $\mathrm{FT}^{\mathrm{C}} \mathrm{C}_{60}$ for ${ }^{\circ} \mathrm{OH}$. The classical Fenton reaction was used to generate hydroxyl radicals, and a spin trapping agent DEPMPO was used to form a stable adduct. The EPR spectrum was acquired, which presented as the signal baseline. As the functionalized $\mathrm{C}_{60}$ (Figure $4 \mathrm{c}$ ) or the conjugate FT- $\mathrm{C}_{60}$ (Figure $4 \mathrm{e}$ ) was added, the peak intensity decreased dramatically in a dose-dependent manner, indicating effective hydroxyl radical scavenging. Similarly, Figure $4 \mathrm{~b}$ illustrated the chemistry mechanism of superoxide radical scavenging by 5-tert-butoxycarbonyl-5-methyl-1pyrroline- $N$-oxide (BMPO), and both functionalized $\mathrm{C}_{60}$ (Figure $4 \mathrm{~d}$ ) and the conjugate FT$\mathrm{C}_{60}$ (Figure 4f) could effectively scavenge the $\mathrm{O}_{2}{ }^{\cdot-}$ radical. Figure $4 \mathrm{~g}$ illustrated the quantitative data of radical scavenging of functionalized $\mathrm{C}_{60}$ and $\mathrm{FT}^{-} \mathrm{C}_{60}$ on ${ }^{\circ} \mathrm{OH}$ and $\mathrm{O}_{2}{ }^{-}$. These data indicated that both the functionalized $\mathrm{C}_{60}$ and the FT-C60 possessed promising antioxidative properties due to their superb radical scavenging capabilities. It was of note that functionalized $\mathrm{C}_{60}$ showed $\sim 61$ and $\sim 83 \%$ signal reduction for ${ }^{\circ} \mathrm{OH}$ and $\mathrm{O}_{2}^{-}{ }^{-}$, respectively, at a concentration of $24 \mu \mathrm{M}$, while conjugate FT-C $_{60}$ at only 8 decreased $\sim 56$ and $71 \%$ of the EPR signal (approximately 3 times stronger scavenging capability than that of functionalized $\mathrm{C}_{60}$ ). This increasing antioxidative potential in $\mathrm{FT}-\mathrm{C}_{60}$ might be contributed by the addition of peptide $\mathbf{1}$ and increased $\mathrm{n}$ bonds on the peptide structure, such as the Cy5 moiety, which stabilized the electrons. 


\subsection{FT- $\mathrm{C}_{60}$ Preferentially Bound toward LPS Stimulated Macrophages in Vitro.}

Macrophages are an integral part of the innate immune system to defend the host against pathogens via their phagocytic ability and play critical contributions to the effector phase of the adaptive immune response. They also play pivotal roles in the initiation and progression of degenerative disc diseases, as abundant macrophages were detected in degenerated discs. FPR-1 is a G protein coupled receptor highly expressed in the phagocytic leukocytes. We have designed a synthetic peptide 1 that specifically binds to the FPR-1 receptor on activated macrophages/monocytes during inflammation. Conjugate FT- $_{60}$ was designed to carry both an FPR-1 targeting moiety and a therapeutic module-an anti-inflammatory and antioxidative nanoparticle $\mathrm{C}_{60}$. To evaluate whether the conjugate $\mathrm{FT}_{-} \mathrm{C}_{60}$ possessed a comparable binding property toward the FPR-1 receptor in macrophages to the peptide itself, we evaluated in vitro binding using a Raw 264.7 macrophage cell line. The Raw 264.7 cell line is a classic cell model to test anti-inflammatory and antioxidative therapeutics in which we have demonstrated abundant induced FPR-1 expression after LPS stimulation. ${ }^{22}$ As shown in Figure 5a,b, the targeting peptide 1 showed a higher fluorescence intensity ( 2.5 times) in LPS-stimulated cells compared to non-LPS treated control $(* * * *<0.0001)$. Similarly, newly developed FT-C 60 also demonstrated preferential binding toward LPS stimulated macrophages (Figure $5 \mathrm{c}, \mathrm{d}$ ). As expected, these results corroborated with elevated FPR-1 expression in activated macrophages via immunofluorescence staining (Figure S8). The FPR-1 binding specificity of peptide 1 with a larger PEG $_{34 \mathrm{k}}$ was previously confirmed in peritoneal macrophages from wild type and FPR-1 ${ }^{-/-}$mouse. ${ }^{14}$ Since FT- $\mathrm{C}_{60}$ exhibited much stronger $\mathrm{Cy} 5$ fluorescence than its targeting peptide alone, we adopted a lower dose of FT- $\mathrm{C}_{60}(100 \mathrm{nM})$ in the cellular binding study compared to the peptide alone $(1 \mu \mathrm{M})$. This data suggested that, after chemical conjugation, the nanoconjugate possessed comparable preferential binding capability to LPS-stimulated FPR-1 expressing macrophages, which laid a solid ground for further evaluation on in vivo targeting.

\subsection{FT- $_{60}$ Exhibited Negligible Cytotoxicity in Macrophages in Vitro.}

Similar to other nanoparticles, physicochemical properties of fullerene and its derivatives are likely to impact their toxicity, including chemical structures, surface modifications, preparation procedures, and exposure doses. In general, nanomaterials that retain $>80 \%$ cell viability are considered safe for use in biological applications. ${ }^{23,24}$ Acute and relative longterm toxicities of the nanoparticles were determined by the DNA assay as an approach to assess the cell viability after treatment of a range of concentrations of nanoconjugates. As shown in Figure 5e,f, DNA contents remained the same between control and FT- $\mathrm{C}_{60}$ treated macrophages after 1 day and 3 days of culture at doses of 25,50 , and $100 \mathrm{nM}$. We further confirmed that commercial fullerol $\mathrm{C}_{60}-\mathrm{OH}$, functionalized $\mathrm{C}_{60}-\mathrm{COOH}$, and targeting moiety peptide 1 at $1 \mu \mathrm{M}$ concentration had no cytotoxicity, corroborating with previous studies by others and us. ${ }^{15,17,19-21}$ Bright-field microscopic images of macrophages subjected to various treatments illustrated a negligible impact on cell morphology and proliferation, as well as the DNA assay shown in the Supporting Information (Figure S9). 


\subsection{FT-C $_{60}$ Effectively Inhibited LPS-Induced Inflammation in Macrophages in Vitro.}

Inflammation plays a crucial role in pain development of intervertebral disc degeneration. ${ }^{25}$ During inflammation, expression and over-production of proinflammatory factors, such as interleukin (IL)-1, IL-6, tumor necrosis factor- $\boldsymbol{a}$ (TNF- $\boldsymbol{a}$ ), and prostaglandin E2 (PGE2), are crucial for triggering progressive activation of immune cells, ${ }^{26}$ which have been significantly correlated with the symptoms of herniated disc disease. ${ }^{13,27}$ In Raw 264.7 macrophages, LPS induced proinflammatory gene expression in a time-dependent fashion (Figure S10). As shown in Figure 6, FT-C 60 significantly attenuated LPS-induced mRNA expression of cytokines, including IL-6 (Figure 6a), TNF- $a$ (Figure 6b), IL-1 (Figure 6c), and COX-II (Figure 6d). Compared to LPS-stimulated cells, FT-C 60 demonstrated a dosedependent protective effect, which was comparable to well-established fullerol $\left(\mathrm{C}_{60}-\mathrm{OH}\right)$ group $(* p<0.05, * * p<0.01, * * * p<0.001$, $* * * * p<0.0001$ vs LPS treated groups) and functionalized $\mathrm{C}_{60}$. These data demonstrated the promising anti-inflammatory effect of the new conjugate $\mathrm{FT}_{-} \mathrm{C}_{60}$ in vitro. ${ }^{28-30}$ Both housekeeping gene GAPDH and ribosome $18 \mathrm{~S}$ were used to normalize expression of genes of interest and yielded similar results (Figure S11). The targeting moiety peptide $\mathbf{1}$ alone did not possess any biological effects under our current experimental conditions (Figure S12).

\subsection{FT- $\mathrm{C}_{60}$ Effectively Alleviated Radicular Pain via Systemic Targeted Delivery in Mice.}

We have previously established an animal model of mouse lumbar radiculopathy secondary to needle puncture induced disc herniation. ${ }^{15,31}$ To better simulate the radiculopathy that occurred in human, we exposed and punctured the L4/5 lumbar disc from the far-lateral left side ensuring herniated nucleus protrusion toward the nearby exposed nerve root. An abundance of inflammatory cells including macrophages is infiltrated to the disc herniation/ nerve root site, initiating a cascade of proinflammatory responses and evoking pain. The von Frey test, developed by the physiologist Maximilian von Frey, is a method of evaluating mechanical allodynia (painful sensation caused by innocuous stimuli like light touch) in mice and rats and a well-established and commonly adopted method for determining mechanical thresholds in mice. To test the analgesic effect of FT- $\mathrm{C}_{60}$, we administered FT$\mathrm{C}_{60}$ into the mice via tail vein after surgery and evaluated pain sensitivity via a von Frey filament-based assay every other day post-surgery. ${ }^{32}$ It was very intriguing that a single intravenous injection of $\mathrm{FT}^{-\mathrm{C}_{60}}$ (10 $\mathrm{nmol}$ per $20 \mathrm{~g}$ mice) effectively diminished ipsilateral mechanical hyperalgesia (pain sensation, lower withdrawal threshold suggests higher pain level) for up to POD 12, similar to intraoperative local administration of fullerol (Figure 7a). For the contralateral mechanical threshold, no significant difference was observed between systemic FT- $\mathrm{C}_{60}$ and local $\mathrm{C}_{60}$ application (Figure 7b). Continuous monitoring of animal body weights revealed that both local $\mathrm{C}_{60}$ administered and injury only groups demonstrated a slight decline of weight (POD 0-8) and then an upward recovery tendency, whereas the FT- $\mathrm{C}_{60}$ treated group maintained a relatively stable trend over the experimental period (Figure 7c). In addition, we clearly visualized much stronger hind leg strength and faster movement in the FT- $\mathrm{C}_{60}$ treated group compared to the injury only group on POD 6 (Video S1). Ex vivo near-infrared fluorescence imaging (NIRF) of the mouse spine clearly depicted focal accumulation of FT- $\mathrm{C}_{60}$ toward inflammatory infiltration sites of the injured disc on POD 7 and POD 14. As shown in Figure 7d and Figure S13, a strong fluorescence signal 
was clearly discernible on the anterior ipsilateral (left, red arrow indicated) site where the disc was punctured. With the assistance of visualization using a surgical microscope, semiquantitative analysis of ex vivo NIRF imaging confirmed targeted FT-C 60 accumulation near the ipsilateral puncture site $(\sim 3$-fold $)$, compared to the contralateral side of the punctured disc $(* p<0.05)$ (Figure 7e). These results corroborated with our prior study that a similar FPR-1 targeting peptide (with the same sequence of amino acid but different length and position of PEG) possessed preferential binding to abundant inflammatory cells, such as macrophages around the local disc herniation site in mice. ${ }^{14}$ With small animal NIRF and single photon emission computed tomography (SPECT) imaging, we also demonstrated specificity of cFlFlF binding to the FPR-1 receptor in detecting local infiltrates at disc hernia using FPR $1^{-/-}$mice. ${ }^{14}$ The semiquantitative organ distribution profile illustrated dynamic hepatobiliary clearance of FT- $\mathrm{C}_{60}$ after intravenous administration for 1 week and 2 weeks using IVIS fluorescence imaging, grounding for further pharmacodynamic/kinetic explorations (Figure 7f, Figure S14). NIRF fluorescence signal intensities were presented as average radiant efficiency $\left(\left[\mathrm{p} / \mathrm{s} / \mathrm{cm}^{2} / \mathrm{sr}\right] /\left[\mu \mathrm{W} / \mathrm{cm}^{2}\right]\right)$. These data suggested that systemic delivery of FT- $\mathrm{C}_{60}$, even at a single administration, could effectively alleviate pain in our animal model of lumbar radiculopathy up to 12 days post injection. Such a long-lasting therapeutic effect of $\mathrm{FT}_{-} \mathrm{C}_{60}$ might be attributed to its targeted accumulation to the disc-ofinterest site and relatively long half-life in circulation, which appeared as a superior property of FT- $\mathrm{C}_{60}$ to other medications due to the chronic nature of degenerative disc diseases and back pain.

\subsection{FT- $\mathrm{C}_{60}$ Potentially Reduced Tissue Volume of Inflammatory Infiltration.}

We further conducted the histological analysis to assess whether FT- $\mathrm{C}_{60}$ possessed an antiinflammatory property at the tissue level in our animal model. As shown in Figure 8a,b, massive cell infiltration was observed in the left lateral tissue near the nerve root around the needle puncture trajectory. In addition, a typical chondrogenic change at the disc hernia site was detected in the injured group along with abundant inflammatory infiltration in the surrounding tissue (Figure S15). Customized quantitative histology analysis (Figure S16) was employed on axial spine sections where both degenerative discs and massive inflammatory cell infiltration were present in the injury side near the exposed nerve root. The results affirmed that systemic FT- $\mathrm{C}_{60}$ dramatically reduced calculated inflammatory tissue volume versus the injury only group on POD 7 (Figure 8c,d). As shown in Figure 8e, safranin-O staining showed typical disc degeneration phenotype with loss of NP cells, disoriented annulus fibrosus (AF), and needle puncture trajectory in injured discs of both groups. It was still not clear whether $\mathrm{FT}^{-\mathrm{C}_{60}}$ promoted disc regeneration since our focus of this study was to test the effect of pain relief in acute disc herniation. Although the histological analysis presented here was semiquantitative, it demonstrated a promising antiinflammatory potential of systemic administered $\mathrm{FT}^{-\mathrm{C}_{60}}$, corroborating with aforementioned in vitro data and our prior studies. ${ }^{15,20,31,33}$ In addition, we did not observe any toxicity based upon gross animal behaviors within our in vivo experimental setting. More systemic toxicity studies shall be in sought of when further translation investigation is on the horizon. 


\section{CONCLUSIONS}

Existing anti-inflammatory treatments for discogenic pain, such as nonsteroidal antiinflammatory drug and epidural spinal injection, are problematic in efficacy and safety. Due to repetitive screening and evaluation by various clinical departments, patients have to wait for 7-9 weeks for an injection to be performed by a trained physician under a fluoroscope with an inconsistent outcome. Systemic and target delivery, on the other hand, can be simply delivered via the peripheral vein by a nurse at a clinic or in an emergency room after disc herniation is diagnosed with MRI, leading to reduced medical cost and improved clinical outcome.

Driven by this critically unmet clinical needs, we successfully synthesized and characterized a novel FPR-1 targeting FT- $\mathrm{C}_{60}$ conjugate that possessed superior targeting properties to highly expressed FPR-1 receptors on infiltrated inflammatory cells (such as on macrophages in our study) and promising anti-inflammatory traits of the $\mathrm{C}_{60}$ nanoparticle. We also demonstrated its potent radical scavenging activities via electron paramagnetic resonance spectroscopy. In vitro evaluation of $\mathrm{FT}_{-} \mathrm{C}_{60}$ showed its robust anti-inflammatory effects in macrophages with negligible cytotoxicity. In vivo animal studies further depicted effective pain alleviation after a single dose of intravenous injection of $\mathrm{FT}^{-\mathrm{C}_{60}}$ in a mouse model of lumbar radiculopathy. Meanwhile, fluorescence molecular imaging confirmed the preferential accumulation and long-lasting half-life in blood circulation given its built-in near-infrared fluorophore. Last but not the least, histological analysis corroborated its antiinflammatory effects at the tissue level.

As a promising and potential pharmaceutical nanoparticle for discogenic low back pain, the newly synthesized nanoparticle $\mathrm{FT}-\mathrm{C}_{60}$ possesses a unique and intrinsic theranostic property during this developmental phase. The specific ligand-receptor binding property of the nanoparticle ensures target delivery by systemic administration. The near-infrared fluorescence tag allows us to visualize and track the drug accumulation and distribution in vivo. Although the fluorophore might be replaced with radioisotope or MRI responsive elements to endow more sensitive detection and translation potential, the increased complexity of the chemistry protocol and altered pharmacokinetic/dynamic profile shall be considered for future translational application. In summary, the successful synthesis and preclinical investigation proved the concept that this novel nanomaterial FT- $\mathrm{C}_{60}$ holds great scientific promise to treat lumbar radiculopathy in a systemic and targeted fashion.

\section{EXPERIMENTAL METHODS}

\subsection{Preparation of the Functionalized $\mathrm{C}_{60}$.}

The functionalizetion of the carboxyl groups and hydroxyl groups onto $\mathrm{C}_{60}$ was performed following a previously reported procedure. ${ }^{34} \mathrm{C}_{60}(30 \mathrm{mg})$ and succinic acid acyl peroxide (49 mg, 5 equiv.) was dissolved in $15 \mathrm{~mL}$ of $o$-dichlorobenzene. The resulting solution was deaerated with flowing argon and heated at $84{ }^{\circ} \mathrm{C}$ for $120 \mathrm{~h}$. Additional succinic acid acyl peroxide (5 equiv.) was added every $12 \mathrm{~h}$. $\mathrm{NaOH}(50 \mathrm{~mL} 0.2 \mathrm{M})$ was added to the resulting brown sludge to extract the water-soluble product (Figure 2b), resulting in two layers. The 
top layer, containing the water-soluble $\mathrm{C}_{60}$ derivative, was concentrated and purified via a Sephadex G-25 size-exclusion gel column.

\subsection{Chemical Conjugation of $\mathrm{FT}-\mathrm{C}_{60}$.}

The peptide was conjugated to the functionalized $\mathrm{C}_{60}$ with a microwave-assisted liberty peptide synthesizer. In specific, $0.4 \mathrm{mg}$ of fullerene $(0.56 \mu \mathrm{mol}), 0.75 \mathrm{mg}$ of peptide $(0.26$ $\mu \mathrm{mol}$ ), $0.1 \mathrm{mg}$ of $O$-(7-azabenzotriazol-1-yl)- $N, N, N^{\prime}, N^{\prime}$-tetramethyluronium hexafluorophosphate (HATU) $(0.26 \mu \mathrm{mol})$, and $0.75 \mu \mathrm{L}$ of DIEA $(4.32 \mu \mathrm{mol})$ were dissolved in $4 \mathrm{~mL}$ of DMSO and allowed to react under microwave for $10 \mathrm{~min}$ at $75{ }^{\circ} \mathrm{C}$ (CEM liberty 1 microwave system). The resulting solution was filtered through polyacrylamide desalting columns and further purified via HPLC, using a gradient of $10-80 \% \mathrm{MeCN} / 0.1 \%$ formic acid as the B solvent on a $\mathrm{C} 18$ reversed-phase column. Water/0.1\% formic acid was used as the A solvent. Collected fractions were characterized with MALDI-TOF mass spectrometry and lyophilized as bluish powder for further characterization and biological tests (see the Supporting Information). The XPS survey spectra were collected by a PHI VersaProbe III scanning XPS microscope, Spectra Research Corporation.

\subsection{EPR Detection of Radical Scavenging Capability.}

The EPR method was coupled with a spin-trapping agent DEPMPO. Hydroxyl radicals were generated by the classical Fenton reaction, which involves the reaction of $\mathrm{FeSO}_{4}(5 \mathrm{mM})$ and $\mathrm{H}_{2} \mathrm{O}_{2}(25 \mathrm{mM})$. DEPMPO $(2.5 \mathrm{mM})$ was used to bind short-lived $\mathrm{OH}$ to form a more stable adduct and allow the detection of EPR signals. Water, different concentrations of the functionalized $\mathrm{C}_{60}$, or the conjugate $\mathrm{FT}-\mathrm{C}_{60}$ was added to the Fenton reaction solution before the addition of DEPMPO. The EPR assays were carried out at $20{ }^{\circ} \mathrm{C}$ using a Bruker ELEXSYS-II EPR spectrometer. Cclear quartz capillary tubes (ID $1.0 \mathrm{~mm}$, OD $1.2 \mathrm{~mm}$ ) were used as the sample container. The EPR data were collected at ambient temperature, 2 min after initiating the formation of $\mathrm{OH}$ by the addition of $\mathrm{FeSO}_{4}$. The following instrument settings were used for collecting EPR spectra: microwave frequency of $9.88 \mathrm{GHz}$, microwave power of $20.02 \mathrm{~mW}$, field modulation frequency of $100 \mathrm{kHz}$, and modulation amplitude of $2 \mathrm{G}$.

To test the superoxide radical anion $\left(\mathrm{O}_{2}{ }^{\cdot-}\right)$ scavenging activity, BMPO was used to trap and detect $\mathrm{O}_{2}{ }^{\cdot-}$ by EPR spectroscopy. The superoxide radical anion was generated using the xanthine/xanthine oxidase system. The radical scavenger reaction was initiated by the addition of xanthine oxidase solution (XOD). The reaction contained $20 \mathrm{mM}$ xanthine (1 M $\mathrm{NaOH}$ in PBS), $20 \mathrm{mM}$ BMPO, $20 \mathrm{mM}$ DTPA, and $4 \mathrm{U} / \mathrm{mL}$ XOD in the presence or absence of the functionalized $\mathrm{C}_{60}$ and the nanoconjugate FT- $\mathrm{C}_{60}$. The EPR spectra were recorded at 2 min after initiating the generation of $\mathrm{O}_{2}{ }^{-}$by the addition of XOD. The instrument settings used were the same as hydroxyl radicals.

\subsection{In Vitro Cell Viability Assessment.}

In brief, Raw 264.7 macrophages were cultured in 96 well plates (tissue culture treated, Thermo Fisher Scientific, Waltham, MA) at $37{ }^{\circ} \mathrm{C}$ for $24 \mathrm{~h}$. Cells were cultured with various treatments (fullerol $\mathrm{C}_{60}-\mathrm{OH}(1 \mu \mathrm{M})$, carboxyl- $\mathrm{C}_{60}(1 \mu \mathrm{M})$, peptide- $\mathrm{C}_{60}$ conjugate FT- $\mathrm{C}_{60}$ $(25,50$, and $100 \mathrm{nM})$, and peptide only $(1 \mu \mathrm{M})$ for 1 and 3 days. At various time points, 
microscopic images of cells were taken at a magnification of 200x. At the end of experiments, cells were lysed with $0.1 \%$ Triton X-100 in PBS. The DNA assay was performed with a Hoechst dye and measured on a Hoefer DyNA Quant 200 spectrometer using calf thymus DNA as a standard. ${ }^{10}$ Four repeated measurements were performed for each sample, and three biological replicate samples were tested for each treatment condition. The Hoechst dye enhanced fluorescence signal of each group was normalized to the value of the untreated control group at all time points.

\subsection{In Vitro Binding of FT-C 60 to Macrophages.}

Raw 264.7 macrophages were seeded on a Lab-Tek 16 well chamber (Thermo Fisher Scientific, Waltham, MA) at a density of $1 \times 10^{5}$ cells per well in $0.5 \mathrm{~mL}$ of complete growth media at $37{ }^{\circ} \mathrm{C}$ overnight. Cells were treated with or without LPS $(100 \mathrm{ng} / \mathrm{mL})$ for 5 $\mathrm{h}$. Then cell media was replaced with fresh serum-free DMEM containing either peptide 1 (1 $\mu \mathrm{M})$ or FT- $\mathrm{C}_{6} 0(100 \mathrm{nM})$ in both control and LPS treated groups and incubated at $37{ }^{\circ} \mathrm{C}$ for another $30 \mathrm{~min}$. Cells were then fixed with $4 \%$ paraformaldehyde (PFA) for $10 \mathrm{~min}$ at room temperature. Cells were washed with PBS and mounted with Vectashield antifade mounting media (w/ DAPI) (Vector Laboratories, Burlingame, CA). Fluorescence images were taken with a confocal fluorescence microscope (LSM 510-UV, Carl Zeiss, Germany) and processed by LSM Image Browser software (Carl Zeiss, Germany). ${ }^{30}$

\subsection{Cell Treatment, RNA Isolation, Reverse Transcription, and Real-Time Reverse Transcription Polymerase Chain Reaction.}

Raw 264.7 cells were seeded onto 48 well plates at a density of $1 \times 10^{5}$ cells $/ \mathrm{mL}$ and cultured for 1-2 days until 90\% confluency. Cells were pretreated with peptide $1(1 \mu \mathrm{M})$, functionalized $\mathrm{C}_{60}(1 \mu \mathrm{M})$, or FT- $\mathrm{C}_{60}(25,50,100 \mathrm{nM})$ in serum-free DMEM for $20 \mathrm{~h}$ and then stimulated with LPS $(100 \mathrm{ng} / \mathrm{mL})$ for $5 \mathrm{~h}$. Total RNA was isolated with the Trizol reagent (Invitrogen) and quantified with a NanoDropTM 1000 spectrophotometer (Thermo Fisher Scientific, Waltham, MA). The cDNA was subsequently synthesized with the iScript cDNA synthesis kit (Bio-Rad Laboratories, Hercules, CA) using $1 \mu \mathrm{g}$ of total RNA following the manufacturer's instruction. Real-time reverse transcription polymerase chain reaction (RT-PCR) was performed with an RT2 SYBR Green Fluo FAST Mastermix (Qiagen Sciences, Germantown, MA) and a QuantStudio3 Real-time PCR system (Applied Biosystems by Thermo Fisher Scientific). Each qPCR reaction solutions were prepared by $10 \mathrm{ng}$ of cDNA, $5 \mu \mathrm{M}$ desired primer, and SYBR Premix Ex Taq $(1 \times)$ in a total volume of $12.5 \mu \mathrm{L}$ with 35 cycles. The mRNA expressions of IL-6, IL-1, COX-2, iNOS, and TNF- $a$ were evaluated. The $18 \mathrm{~S}$ rRNA and GAPDH were used as internal controls. Sequences of primers, individual annealing temperature, and amplicon lengths were the same as previously reported and are listed in Table S1.

\subsection{Mouse Disc Herniation Induced Radiculopathy.}

B6 mice were purchased from Charles River (Indianapolis, IN, USA, 8-10 weeks old, male, 20-25 g). Animal use was approved by the Institutional Animal Care and Use Committee at the University of Virginia. General anesthesia was induced with intraperitoneal injection of ketamine/xylazine $(60-80 / 5-10 \mathrm{mg} / \mathrm{kg})$. Briefly, using aseptic techniques and a surgical 
microscope, the spine was exposed through an anterior midline transperitoneal approach. After separating the hind peritoneum and psoas major muscle, the L4 and L5 vertebral bodies were identified. The left L5 nerve root was exposed by removing the overlying psoas muscle fibers, and the L4-5 disc was punctured laterally to enable nucleus protrusion toward the L5 nerve root. Animals were randomly assigned to three groups: injured $(n=12)$ (treated with saline), local $\mathrm{C}_{60}(n=12)$, and systemic $\mathrm{FT}_{-\mathrm{C}_{60}}(n=12)$. For the injured group, physiological saline $(10 \mu \mathrm{L})$ was added dropwise onto the herniated disc puncture. For the local $\mathrm{C}_{60}$ group, freshly prepared fullerol $\mathrm{C}_{60}$ solution $(10 \mu \mathrm{L}, 1 \mu \mathrm{M}$ in distilled and deionized water) was applied dropwise using a syringe onto the herniated disc. For the systemic nanoconjugate group, $10 \mathrm{nmol}$ per $20 \mathrm{~g}$ of mice of FT- $\mathrm{C}_{60}$ in saline was intravenously injected via the tail vein 1-2 $\mathrm{h}$ after mice woke up from surgeries. A shamoperated group $(n=5)$ with nerve exposure but without a disc puncture was performed prior to the above surgeries to establish a baseline for mechanical hyperalgesia. The shamoperated group exhibited unchanged baselines as previously published by us ${ }^{15,20,31}$.

\subsection{Electronic von Frey Test.}

To assess the mechanical sensitivity of animals subjected to disc herniation with or without treatment, the electronic von Frey test was performed on both hind paws for 3 consecutive days prior to surgery and every other day up to POD 12 in a blinded fashion, following reported protocol. ${ }^{31,32}$ In brief, mice were acclimated on an elevated mesh grid, and the hind paw withdrawal threshold was determined using the electronic von Frey apparatus. ${ }^{35}$ Five trials were conducted on each paw, with at least 5 min of rest time between trials on opposite paws and 10 min between trials on the same paw. For each paw, the mechanical withdrawal thresholds from five trials were averaged after excluding the maximum and minimum reading. Both ipsilateral and contralateral mechanical thresholds of all groups were measured, and the mean threshold value of each group was averaged at each time point.

\subsection{Ex Vivo Near-Infrared Fluorescence Imaging of Mouse Spine and Organs.}

At 1 and 2 weeks of post-surgery, mice were euthanized with $100 \% \mathrm{CO}_{2}$. Lumbar spines were harvested under a surgical microscope to locate the injured disc level. Ex vivo imaging of lumbar spines and organs (heart, liver, spleen, lung, kidneys, muscle, brain, bone, brain, and fat) from all groups was performed with the epifluorescence function using Xenogen IVIS Spectrum and Live Image software. ${ }^{14,33,36-40}$

\subsection{Histological Staining.}

Lumbar spines were fixed in $10 \%$ formalin, decalcified in $0.25 \mathrm{M}$ ethylenediaminetetraacetic acid (EDTA) for 2 weeks, embedded in paraffin, and sectioned either trans-axially or midsagittally ( $5 \mu \mathrm{m}$ thickness). Three sections were collected on each glass slide. For axial section samples, safranin-O $(0.1 \%)$ staining was performed on every five slides to detect the disc degenerative change to visualize both injured disc and anterior inflammatory cell infiltration on the same plane. Visual examination under a microscope was carefully conducted to locate the entire range of spine sections encompassing the injured disc level and anterior inflammatory infiltration areas, as this was a critical step to evaluate severity of inflammation in each group. For sagittal sections, alcian blue/picrosirious red staining was performed using $1 \%$ alcian blue solution $(\mathrm{pH} 2.5)$ and picrosirius red $(0.1 \%$ sirius red in 
saturated aqueous picric acid) for alcian blue/picrosirius red staining following the published protocol. ${ }^{14,15,31}$

\subsection{Quantification of Cell Infiltration.}

All microscopic images were taken by a Nikon ECLIPSE E600 with Nikon Elements. Representative images of fields of interest were taken at magnifications of $40 \times, 100 \times$, and $200 \times$ to visualize both gross anatomic structure and cell composition details. At a magnification of $100 \times$, all areas of anterior inflammatory infiltration of every stained slide (one image was taken every 15 sections) were recorded first and then subjected to quantitative analyses. First of all, the color hue setting was set to 64 to provide the best contrast. Free-draw regions of interest (ROI) that adequately included the entire quantifiable inflammatory cell infiltration and excluded the large, blank, bony, and disc area was applied and analyzed. A previously optimized object count threshold for area quantification (brown and blue in this case) was loaded and kept consistent throughout quantification. The analysis output from built-in software for each ROI contained a total area (total area of selected ROI) and a color intensity ratio of brown to blue. The color intensity ratio of brown to blue was calculated for each group, representing the area percentage of inflammatory tissue to total ROI. For each ROI, the area of inflammatory tissue was obtained by total area times the percentage. An area $A_{\text {trans }}$ (infiltration area of trans-axial images on every 15 slides) value was obtained by summing up infiltration areas of all ROIs. For each mouse lumbar spine sample, 300 trans-axial sections were collected to cover the entire affected disc with inflammatory infiltrations in the surroundings. Each $A_{\text {trans }}$ represented different values due to the irregular shape of inflammatory cell infiltration. A small volume of inflammation tissue $V_{\text {small }}$ was then calculated by (given the tissue between \#30 to \#45 as an example) 0.5 $\times$ (infiltration area of section \#30 + infiltration area of section \#45) $\times 15$ sections $\times 5 \mu \mathrm{m} /$ section (1)

The total volume of inflammatory tissue $V_{\text {infil }}$ for each spinal sample was then obtained by adding up all $V_{\text {small }}$. Three to four mouse spinal samples were analyzed per group.

\subsection{Statistical Analysis.}

All in vitro experiments were performed in triplicate. Quantitative data were presented as mean \pm SEM. One-way ANOVA and multiple comparisons were used to analyze PCR and pain data using GraphPad Prism. Data comparing two groups were analyzed with Student's $t$ test. A $p$ value less than 0.05 was considered as statistically significant.

\section{Supplementary Material}

Refer to Web version on PubMed Central for supplementary material.

\section{ACKNOWLEDGMENTS}

We are grateful to financial support from US NIH NIAMS R01AR064792, R21AR057512, Commonwealth Health Research Board (CHRB), Orthopaedic Trauma Association, and North American Spine Society (NASS), and startup fund from the Department of Orthopaedic Surgery at the University of Virginia. 


\section{REFERENCES}

(1). Freburger JK; Holmes GM; Agans RP; Jackman AM; Darter JD; Wallace AS; Castel LD; Kalsbeek WD; Carey TS The Rising Prevalence of Chronic Low Back Pain. Arch. Intern. Med 2009,169, 251-258. [PubMed: 19204216]

(2). Hurwitz EL; Randhawa K; Yu H; Cote P; Haldeman S. The Global Spine Care Initiative: a Summary of the Global Burden of Low Back and Neck Pain Studies. Euro. Spine J 2018, 27 , 796-801.

(3). Balague F; Mannion AF; Pellise F; Cedraschi C. Non-specific Low Back Pain. Lancet 2012, 379, 482-91. [PubMed: 21982256]

(4). Schwarzer AC; Aprill CN; Derby R; Fortin J; Kine G; Bogduk N. The Prevalence and Clinical Features of Internal Disc Disruption in Patients with Chronic Low Back Pain. Spine 1995, 20, 1878-1883. [PubMed: 8560335]

(5). Goupille P; Jayson MIV; Valat J-P; Freemont AJ The Role of Inflammation in Disk Herniationassociated Radiculopathy. Semin. Arthritis Rheum 1998, 28, 60-71. [PubMed: 9726337]

(6). Molinos M; Almeida CR; Caldeira J; Cunha C; Goncalves RM; Barbosa MA Inflammation in Intervertebral Disc Degeneration and Regeneration. J. R. Soc., Interface 2015, 12, 2014119120141191.

(7). Koes BW; van Tulder MW; Peul WC Diagnosis and Treatment of Sciatica. BMJ 2007, 334, 13131317. [PubMed: 17585160]

(8). Hughes SPF; Freemont AJ; Hukins DWL; McGregor AH; Roberts S. The Pathogenesis of Degeneration of the Intervertebral Disc and Emerging Therapies in the Management of Back Pain. J. Bone Joint Surg. Br 2012, 94-B, 1298-1304. [PubMed: 23015552]

(9). Adams MA; Roughley PJ What is Intervertebral Disc Degeneration, and What Causes It? Spine 2006, 31, 2151-61. [PubMed: 16915105]

(10). Xiao L; Ding M; Saadoon O; Vess E; Fernandez A; Zhao P; Jin L; Li X. A Novel Culture Platform for Fast Proliferation of Human Annulus Fibrosus Cells. Cell Tissue Res. 2017, 367, 339-350. [PubMed: 27623803]

(11). Rothoerl RD; Woertgen C; Brawanski A. Pain Resolution After Lumbar Disc Surgery is Influenced by Macrophage Tissue Infiltration. A prospective Consecutive Study on 177 patients. J. Clin. Neurosci 2002, 9, 633-636. [PubMed: 12604272]

(12). Hamamoto H; Miyamoto H; Doita M; Takada T; Nishida K; Kurosaka M. Capability of Nondegenerated and Degenerated Discs in producing inflammatory agents with or without macrophage interaction. Spine 2012, 37, 161-167. [PubMed: 21494199]

(13). Takada T; Nishida K; Maeno K; Kakutani K; Yurube T; Doita M; Kurosaka M. Intervertebral disc and macrophage interaction induces mechanical hyperalgesia and cytokine production in a herniated disc model in rats. Arthritis Rheum. 2012, 64, 2601-2610. [PubMed: 22392593]

(14). Xiao L; Ding M; Zhang Y; Chordia M; Pan D; Shimer A; Shen F; Glover D; Jin L; Li X. A Novel Modality for Functional Imaging in Acute Intervertebral Disk Herniation via Tracking Leukocyte Infiltration. Mol. Imaging Biol 2017, 19, 703-713. [PubMed: 28050750]

(15). Jin L; Ding M; Oklopcic A; Aghdasi B; Xiao L; Li Z; Jevtovic-Todorovic V; Li X. Nanoparticle fullerol alleviates radiculopathy via NLRP3 inflammasome and neuropeptides. Nanomedicine: NBM 2017, 13, 2049-2059.

(16). Chen BX; Wilson SR; Das M; Coughlin DJ; Erlanger BF Antigenicity of fullerenes: antibodies specific for fullerenes and their characteristics. Proc. Natl. Acad. Sci U. S. A 1998, 95, 1080910813.

(17). Li T; Xiao L; Yang J; Ding M; Zhou Z; LaConte L; Jin L; Dorn HC; Li X. Trimetallic Nitride Endohedral Fullerenes Carboxyl-Gd3N@C80: A New Theranostic Agent for Combating Oxidative Stress and Resolving Inflammation. ACS Appl. Mater. Interfaces 2017, 9, 1768117687.

(18). Xiao L; Li T; Ding M; Yang J; Rodríguez-Corrales J; LaConte SM; Nacey N; Weiss DB; Jin L; Dorn HC; Li X. Detecting Chronic Post-Traumatic Osteomyelitis of Mouse Tibia via an IL-13Ra2 Targeted Metallofullerene Magnetic Resonance Imaging Probe. Bioconjugate Chem. 2017, 28, 649-658. 
(19). Roy P; Bag S; Chakraborty D; Dasgupta S. Exploring the Inhibitory and Antioxidant Effects of Fullerene and Fullerenol on Ribonuclease A. ACS omega 2018, 3, 12270-12283.

(20). Xiao L; Hong K; Roberson C; Ding M; Fernandez A; Shen F; Jin L; Sonkusare S; Li X. Hydroxylated Fullerene: A Stellar Nanomedicine to Treat Lumbar Radiculopathy via Antagonizing TNF-a-Induced Ion Channel Activation, Calcium Signaling, and Neuro-peptide Production. ACS Biomater. Sci. Eng 2018, 4, 266-277. [PubMed: 30038959]

(21). Liu Q; Jin L; Mahon BH; Chordia MD; Shen FH; Li X. Novel Treatment of Neuroinflammation Against Low Back Pain By Soluble Fullerol Nanoparticles. Spine 2013, 38, 1443-1451. [PubMed: 23466506]

(22). Mandal P; Novotny M; Hamilton TA Lipopolysaccharide Induces Formyl Peptide Receptor 1 Gene Expression in Macrophages and Neutrophils via Transcriptional and Posttranscriptional Mechanisms. J. Immunol 2005, 175, 6085-6091. [PubMed: 16237104]

(23). Thomas M; Klibanov AM Conjugation to Gold Nanoparticles Enhances Polyethylenimine's Transfer of Plasmid DNA Into Mammalian Cells. Proc. Natl. Acad. Sci. U. S.A 2003, 100, 9138 9143. [PubMed: 12886020]

(24). Chompoosor A; Saha K; Ghosh PS; Macarthy DJ; Miranda OR; Zhu Z-J; Arcaro KF; Rotello VM The Role of Surface Functionality on Acute Cytotoxicity, ROS Generation and DNA Damage by Cationic Gold Nanoparticles. Small 2010, 6, 2246-2249. [PubMed: 20818619]

(25). Wuertz K; Haglund L. Inflammatory Mediators in Intervertebral Disk Degeneration and Discogenic Pain. Global Spine J. 2013, 3, 175-184. [PubMed: 24436868]

(26). Duque GA; Descoteaux A. Macrophage cytokines: involvement in immunity and infectious diseases. Front. Immunol 2014, 5,491. [PubMed: 25339958]

(27). Meng F; Lowell CA Lipopolysaccharide (LPS)-induced macrophage activation and signal transduction in the absence of Src-family kinases Hck, Fgr, and Lyn. J. Exp. Med 1997, 185, 1661-1670. [PubMed: 9151903]

(28). Gillette DD; Tridandapani S; Butchar JP Monocyte/ macrophage Inflammatory Response Pathways to Combat Francisella Infection: Possible Therapeutic Targets? Front. Cell. Infect. Microbiol 2014, 4, 18. [PubMed: 24600590]

(29). Fang H; Pengal RA; Cao X; Ganesan LP; Wewers MD; Marsh CB; Tridandapani S. Lipopolysaccharide-Induced Macrophage Inflammatory Response Is Regulated by SHIP. J. Immunol 2004, 173, 360-366. [PubMed: 15210794]

(30). Andreakos E; Sacre SM; Smith C; Lundberg A; Kiriakidis S; Stonehouse T; Monaco C; Feldmann M; Foxwell BM Distinct Pathways of LPS-induced NF-kB Activation and Cytokine Production in Human Myeloid and Nonmyeloid Cells Defined by Selective Utilization of MyD88 and Mal/TIRAP. Blood 2004, 103, 2229-2237. [PubMed: 14630816]

(31). Xiao L; Ding M; Fernandez A; Zhao P; Jin L; Li X. Curcumin Alleviates Lumbar Radiculopathy by Reducing Neuro-inflammation, oxidative stress and nociceptive factors. Euro. Cell. Mater 2017, 33, 279-293.

(32). Martinov T; Mack M; Sykes A; Chatterjea D. Measuring changes in tactile sensitivity in the hind paw of mice using an electronic von Frey apparatus. J. Vis. Exp. 2013, e51212.

(33). Xiao L; Zhang Y; Berr SS; Chordia MD; Pramoonjago P; Pu L; Pan D. A Novel Near-Infrared Fluorescence Imaging Probe for in Vivo Neutrophil Tracking. Mol. Imaging 2012, 11, 372-382. [PubMed: 22954181]

(34). Shu C; Corwin FD; Zhang J; Chen Z; Reid JE; Sun M; Xu W; Sim JH; Wang C; Fatouros PP; Esker AR; Gibson HW; Dorn HC Facile preparation of a new gadofullerene-based magnetic resonance imaging contrast agent with high $1 \mathrm{H}$ relaxivity. Bioconjugate Chem. 2009, 20, 11861193.

(35). Bonin RP; Bories C; De Koninck Y. A Simplified Up-Down Method (SUDO) for Measuring Mechanical Nociception in Rodents Using von Frey Filaments. Mol. Pain 2014, 10, 1744-8069.

(36). Guan Y; Zhang Y; Xiao L; Li J; Wang J-P; Chordia MD; Liu Z-Q; Chung LWK; Yue W; Pan D. Improving Therapeutic Potential of Farnesylthiosalicylic Acid: Tumor Specific Delivery via Conjugation with Heptamethine Cyanine Dye. Mol. Pharmaceutics 2017, 14, 1-13. 
(37). Zhang Y; Xiao L; Popovic K; Xie X; Chordia MD; Chung LWK; Williams MB; Yue W; Pan D. Novel Cancer-Targeting SPECT/NIRF Dual-modality Imaging Probe 99mTc-PC-1007: Synthesis and Biological Evaluation. Bioorg. Med. Chem. Lett. 2013, 23, 6350-6354. [PubMed: 24125889]

(38). Xiao L; Zhang Y; Yue W; Xie X; Wang J-P; Chordia MD; Chung LWK; Pan D. Heptamethine Cyanine Based 64Cu-PET Probe PC-1001 for Cancer Imaging: Synthesis and In vivo Evaluation. Nucl. Med. Biologia 2013, 40, 351-360.

(39). Zhang Y; Xiao L; Chordia MD; Locke LW; Williams MB; Berr SS; Pan D. Neutrophil Targeting Heterobivalent SPECT Imaging Probe: cFLFLF-PEG-TKPPR-99mTc. Bioconjugate Chem. 2010, 21, 1788-1793.

(40). Xiao L; Zhang Y; Liu Z; Yang M; Pu L; Pan D. Synthesis of the Cyanine 7 Labeled Neutrophilspecific Agents for Noninvasive Near Infrared Fluorescence Imaging. Bioorg. Med. Chem. Lett. 2010, 20, 3515-3517. [PubMed: 20488705] 


\section{FPR-1 targeting peptide cFIFIF \\ binds $w /$ activated \& infiltrated inflammatory cells near disc herniation}

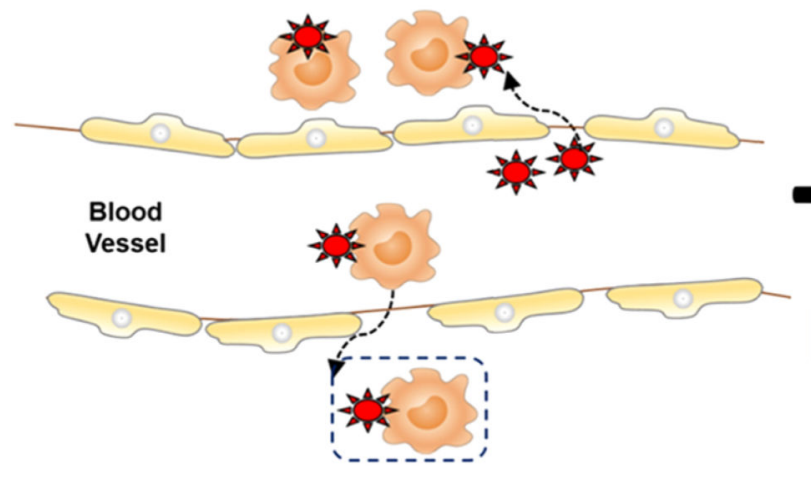

\section{Pleiotropic therapeutic $\mathrm{C}_{60}$}

Immune Responses

Anti-oxidant Anti-inflammation

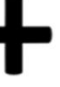
Interver

Anti-oxidant Anti-inflammation Disc restoration
Dorsal Root Ganglia \& Sensory Neurons

Neuroprotection Nociceptive modulation Pain mediation

First-of-its-kind theranostic agent $\mathrm{FT}-\mathrm{C}_{60}$ for systemic treatment of discogenic back/leg pain
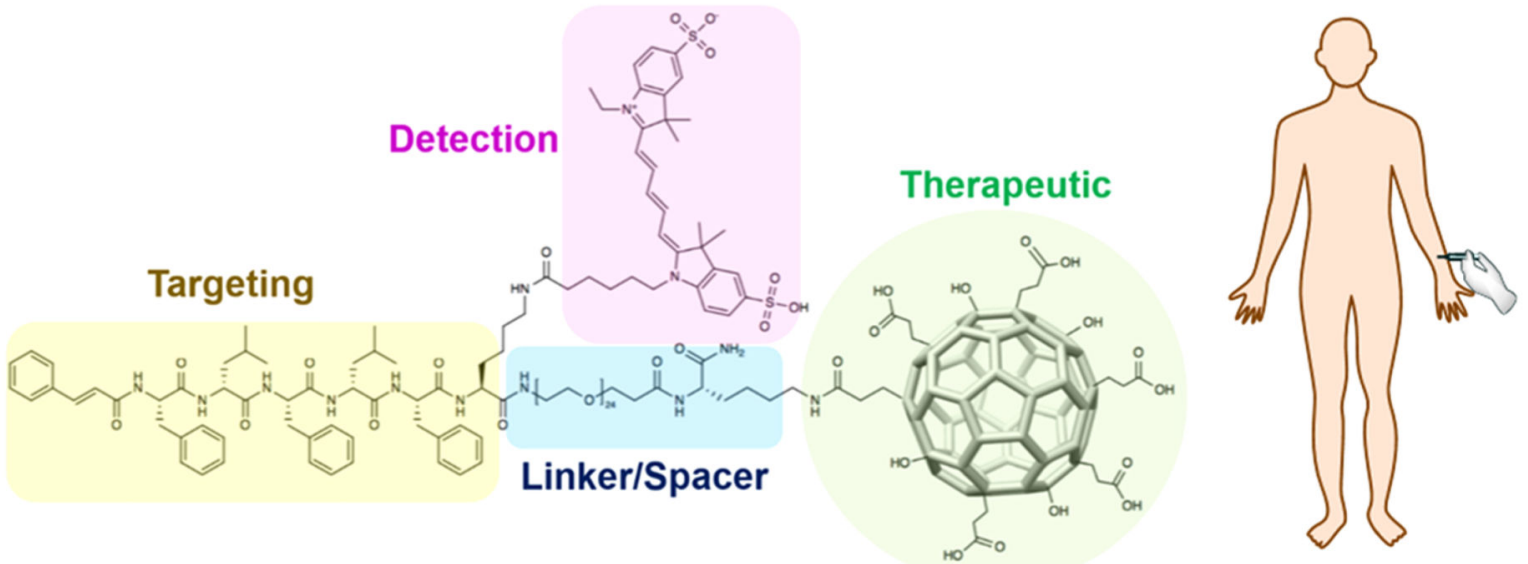

Figure 1.

Schematic illustration on therapeutic and targeting mechanisms of the newly developed firstof-its-kind theranostic nanoparticle $\mathrm{FT}_{-} \mathrm{C}_{60}$, empowering systemic delivery of nanomedicine to treat discogenic back/leg pain. 


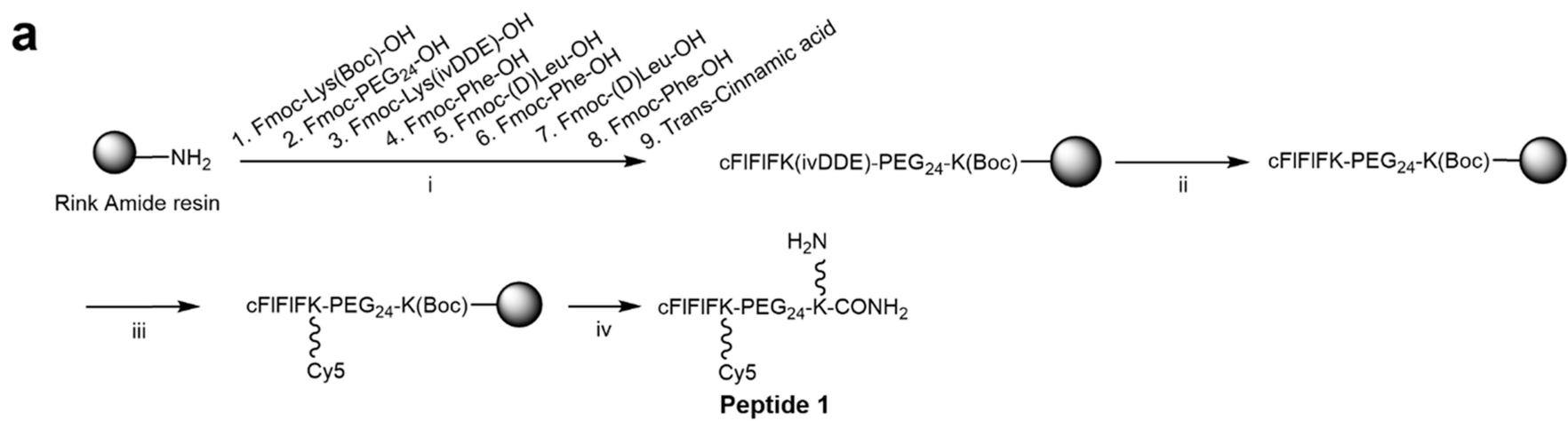

b
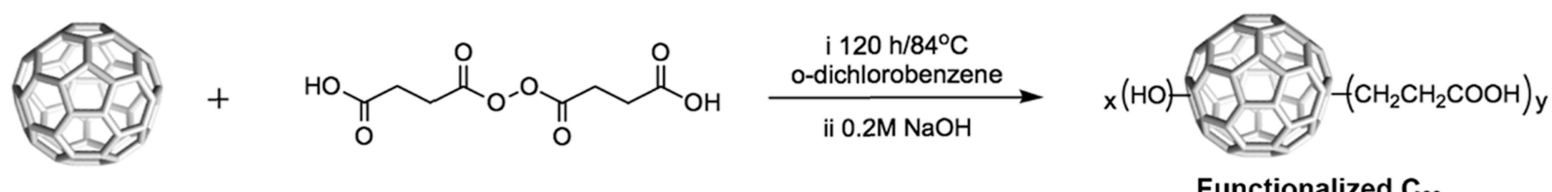

C
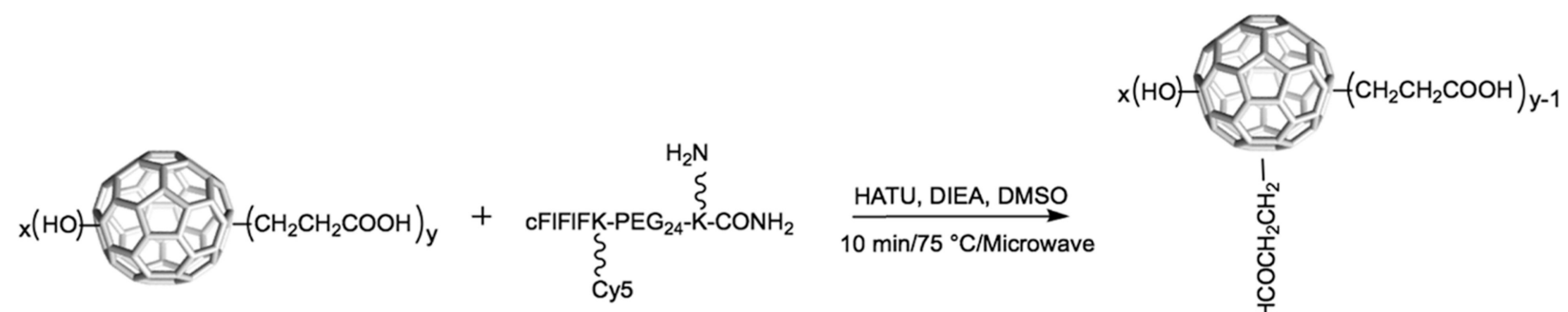

Figure 2.

Synthesis of (a) targeting moiety peptide 1 [cFIFIFK(Cy5) $\mathrm{PEG}_{24} \mathrm{~K}\left(\mathrm{NH}_{2}\right) \mathrm{CONH}_{2}$ ], (b) functionalized $\mathrm{C}_{60}$ and (c) FT- $\mathrm{C}_{60}$ conjugate. Reagents and conditions: $\mathrm{f}$ (a), (i) standard solid-phase Fmoc chemistry; (ii) $2 \% \mathrm{NH}_{2} \mathrm{NH}_{2}$; (iii) $\mathrm{Cy} 5$, DIC, $\mathrm{HOBt}$; (iv) $95 \%$ trifluoroacetic acid (TFA); (b), (i) $o$-dichlorobenzene, $120 \mathrm{~h} / 84^{\circ} \mathrm{C}$ (ii) $\mathrm{NaOH}(50 \mathrm{~mL}, 0.2$ $\mathrm{M})$; (c),HATU (0.26 $\mu \mathrm{mol})$, DIEA (4.32 $\mu \mathrm{mol})$, DMSO, $10 \mathrm{~min} / 75^{\circ} \mathrm{C}$, and microwave (CEM liberty 1 microwave system). The resulting solution was purified by polyacrylamide desalting columns and RP-HPLC. 
a

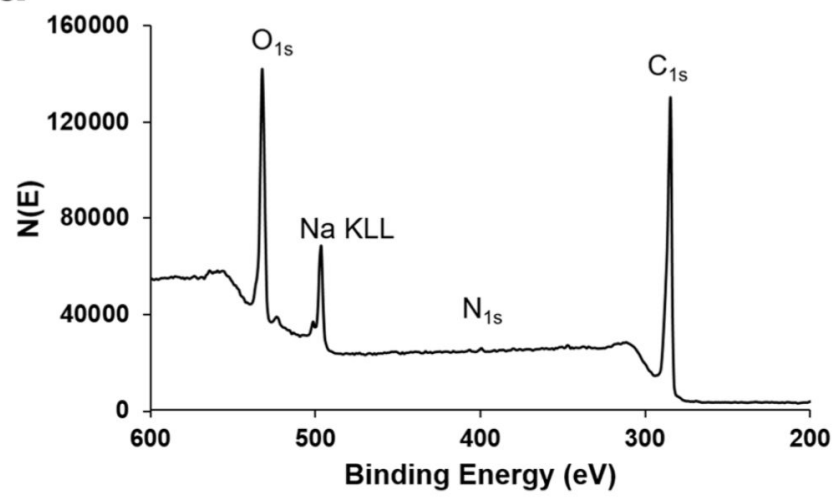

C

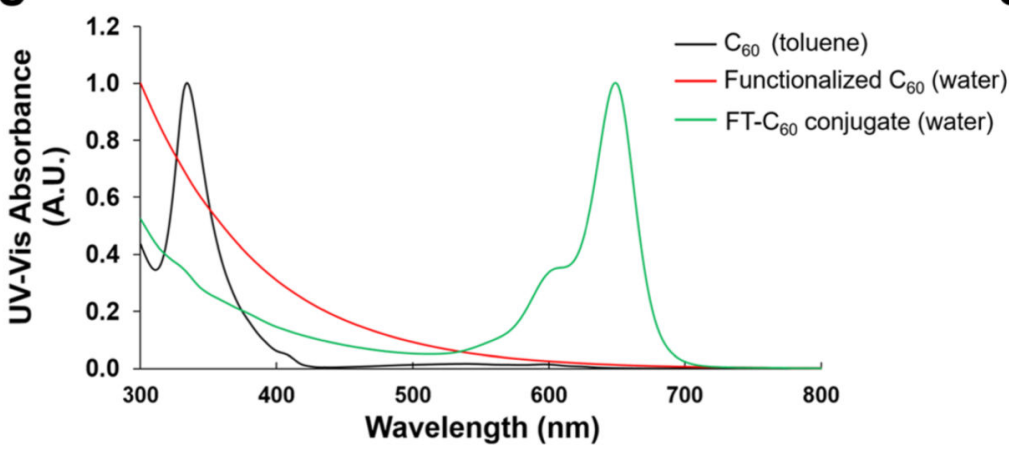

b

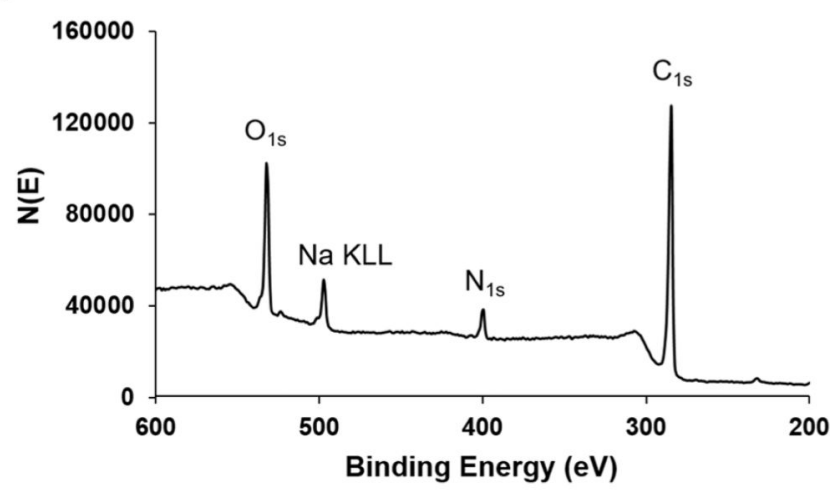

d

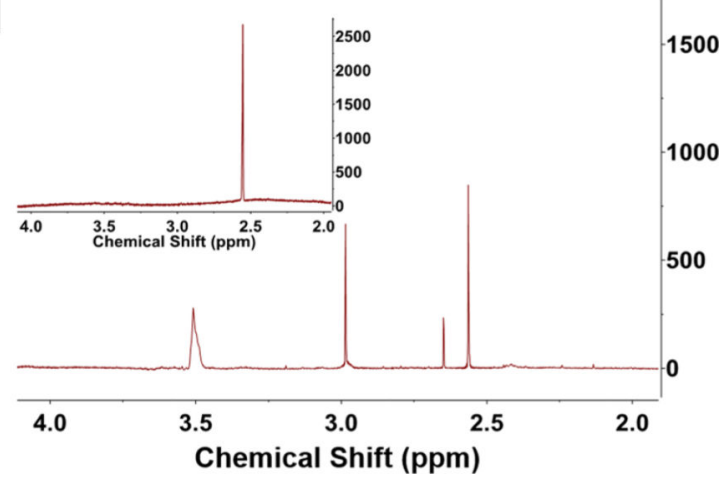

Figure 3.

Characterization of FT- $\mathrm{C}_{60}$ conjugate. XPS survey spectra of (a) functionalized $\mathrm{C}_{60}$ and (b) FT- $\mathrm{C}_{60}$ conjugate. The peak centered at a binding energy value of $400.4 \mathrm{eV}$ represents $\mathrm{N}_{1 \mathrm{~s}}$. The peak intensity of increased significantly after conjugating the peptide to the functionalized $\mathrm{C}_{60}$, indicating the success of the conjugation process. The peaks centered at binding energies of 284.4, 497.4, and $533.4 \mathrm{eV}$ represent $\mathrm{C}_{1 \mathrm{~s}}, \mathrm{Na}$ Auger peak, and $\mathrm{O}_{1 \mathrm{~s}}$, respectively. (c) UV-vis absorbance spectra of $\mathrm{C}_{60}$, functionalized $\mathrm{C}_{60}$, and the FT- $\mathrm{C}_{60}$ conjugate in toluene and water. The $\mathrm{C}_{60}(\mathrm{OH})_{28}\left(\mathrm{CH}_{2} \mathrm{CH}_{2} \mathrm{COOH}\right)_{16}$ lost the characteristic peaks for $\mathrm{C}_{60}$, indicating that the introduction of the functional groups changed the electronic structure. The peak in the range of 600 to $700 \mathrm{~nm}$ was characteristic of the Cy5 on the peptide, which suggested the successful conjugation of the peptide onto the functionalized $\mathrm{C}_{60}$. Blue: $\mathrm{C}_{60}$ in toluene. Red: $\mathrm{C}_{60}(\mathrm{OH})_{28}\left(\mathrm{CH}_{2} \mathrm{CH}_{2} \mathrm{COOH}\right)_{16}$ in water. Green: the conjugate in water. (d) ${ }^{1} \mathrm{H}$ NMR of the FT- $\mathrm{C}_{60}$ conjugate and functionalized $\mathrm{C}_{60}$ (inset) in $\mathrm{D}_{2} \mathrm{O}$. The methylene protons in the functionalized $\mathrm{C}_{60}$ were shown as a singlet at $2.55 \mathrm{ppm}$. The same methylene protons contributed by the functionalized $\mathrm{C}_{60}$ and a PEG proton peak at $3.5 \mathrm{ppm}$ were detected in the ${ }^{1} H$ NMR spectrum of the FT- $\mathrm{C}_{60}$ conjugate, further confirming the conjugation. 
a

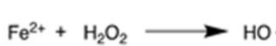

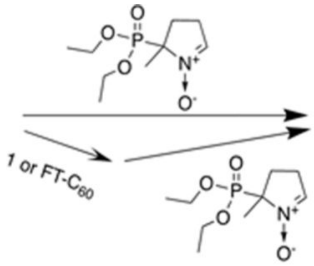

- water

C
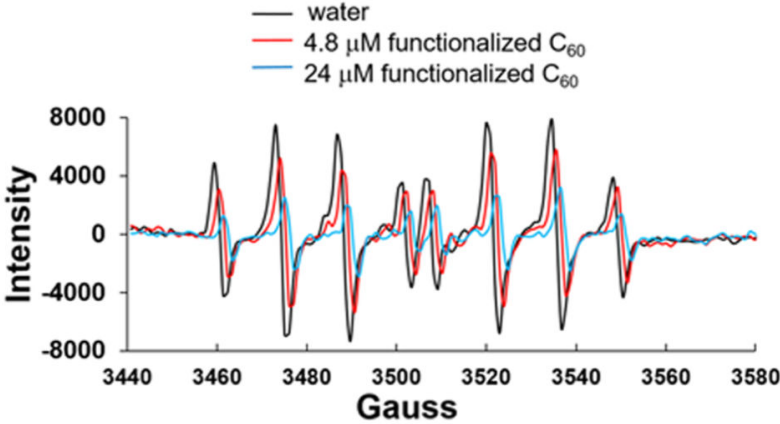

e
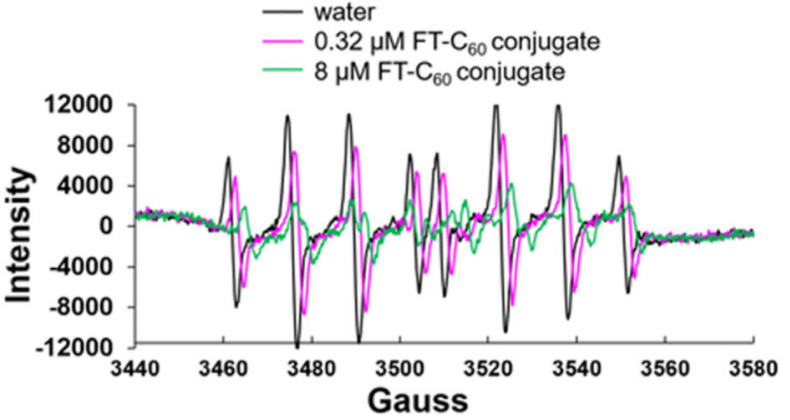

g

\begin{tabular}{|c|c|c|}
\hline Percentage of signal reduction (\%) & $\mathrm{HO} \cdot$ & $\mathrm{O}_{2}{ }^{* *}$ \\
\hline $\mathbf{4 . 8} \mu \mathrm{M}$ functionalized $\mathrm{C}_{60}$ & $18.66 \pm 6.60 \%$ & $64.60 \pm 2.04 \%$ \\
\hline $\mathbf{2 4} \boldsymbol{\mu M}$ functionalized $\mathrm{C}_{60}$ & $61.10 \pm 5.41 \%$ & $83.39 \pm 4.68 \%$ \\
\hline
\end{tabular}
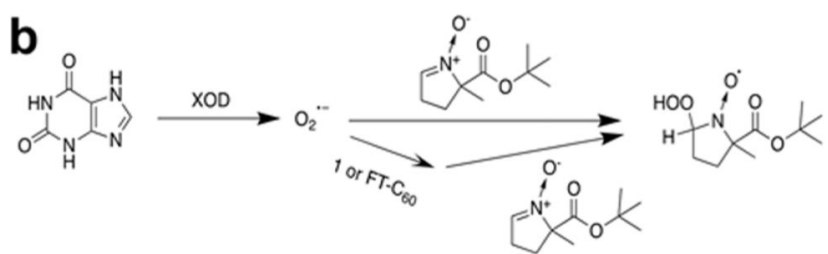

d

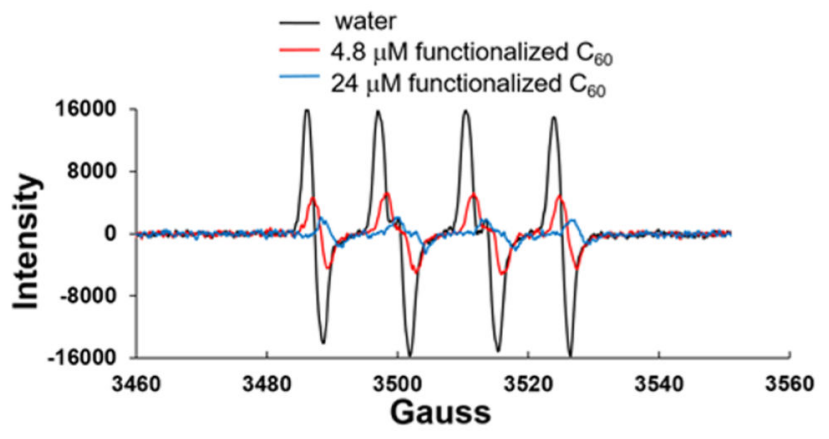

$\mathbf{f}$

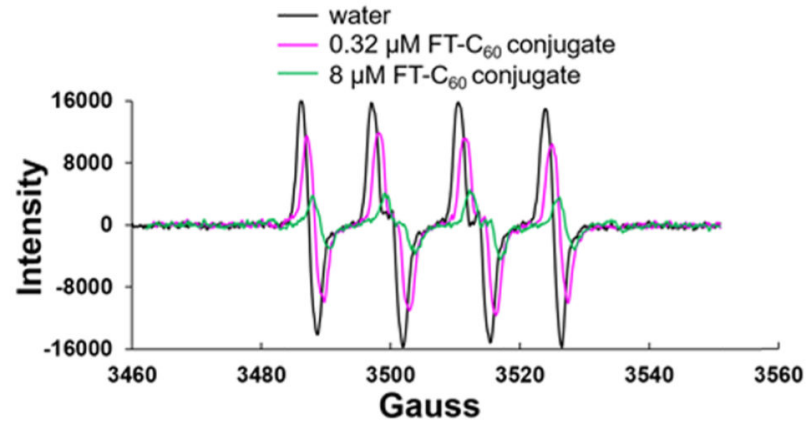

h

\begin{tabular}{|c|c|c|}
\hline Percentage of signal reduction (\%) & $\mathrm{HO} \cdot$ & $\mathrm{O}_{2}{ }^{*}$ \\
\hline $0.32 \mu \mathrm{M}$ FT- $\mathrm{C}_{60}$ conjugate & $27.39 \pm 1.51 \%$ & $27.38 \pm 4.27 \%$ \\
\hline $8 \mu \mathrm{M}$ FT-C 60 conjugate & $56.37 \pm 6.41 \%$ & $71.23 \pm 5.64 \%$ \\
\hline
\end{tabular}

Figure 4.

Both functionalized $\mathrm{C}_{60}$ and FT- $\mathrm{C}_{60}$ conjugate showed robust radical scavenging properties detected by EPR. (a) Mechanism of the hydroxyl radical production by the Fenton reaction and captured by DEPMPO. (b) Mechanism of superoxide radical production by xanthine/ xanthine oxidase (XOD) system and captured by BMPO. EPR spectra of the hydroxyl radical captured by DEPMPO with and without (c) functionalized $\mathrm{C}_{60}$ and (e) FT-C 60 conjugate. EPR spectra of superoxide radicals captured by BMPO with and without (d) functionalized $\mathrm{C}_{6} \mathrm{O}$ and (f) $\mathrm{FT}-\mathrm{C}_{60}$ conjugate. Ultrapure distilled water was used as a control. Table summary of scavenging capabilities of hydroxyl radical and superoxide radical anion by ( $\mathrm{g}$ ) functionalized $\mathrm{C}_{60}$ and (h) FT- $\mathrm{C}_{60}$ conjugate. EPR signal reduction depicted a stronger radical scavenging capability of conjugate $\mathrm{FT}-\mathrm{C}_{60}$ compared to functionalized $\mathrm{C}_{60}$ in a dose-dependent manner. 


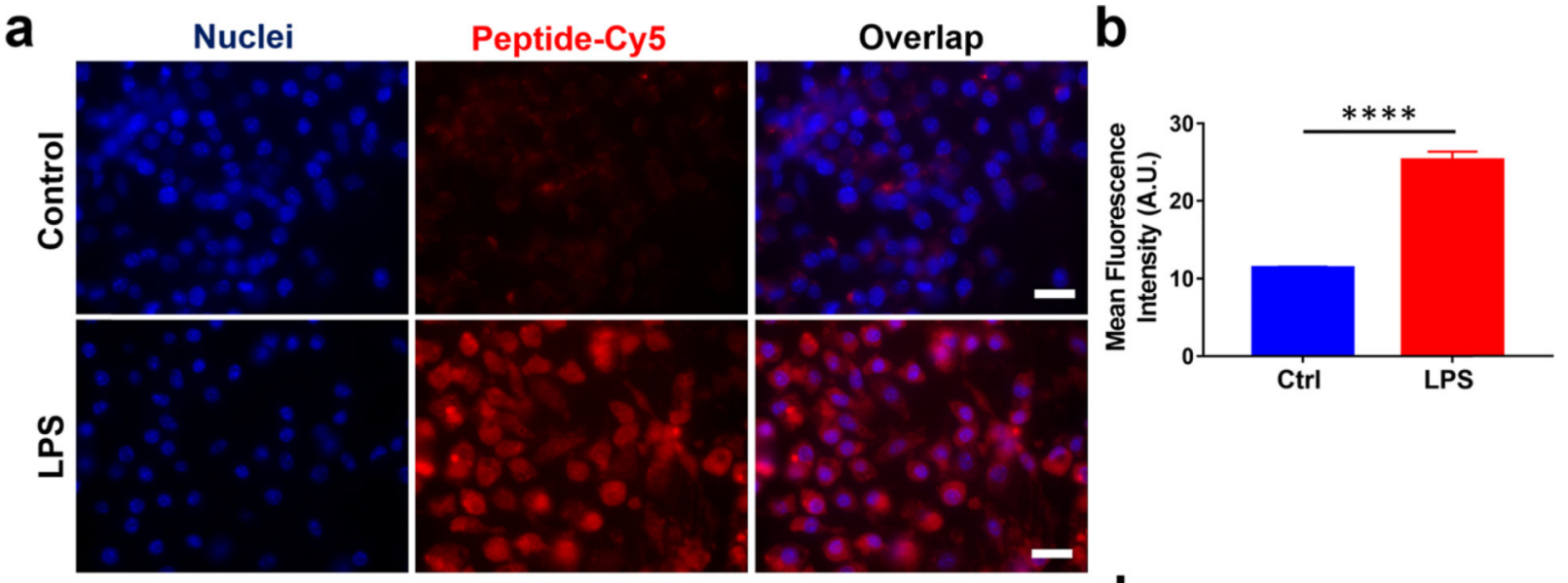

C
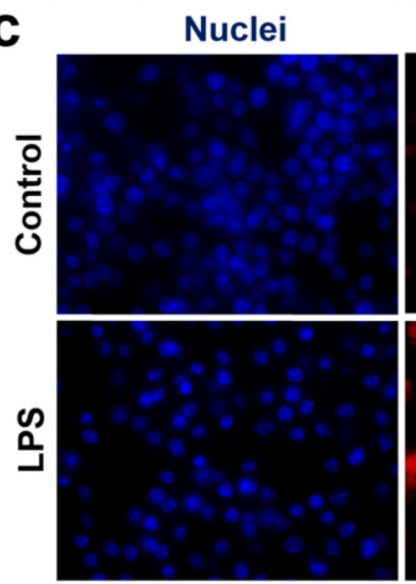

FT- $\mathrm{C}_{60}(\mathrm{Cy} 5)$
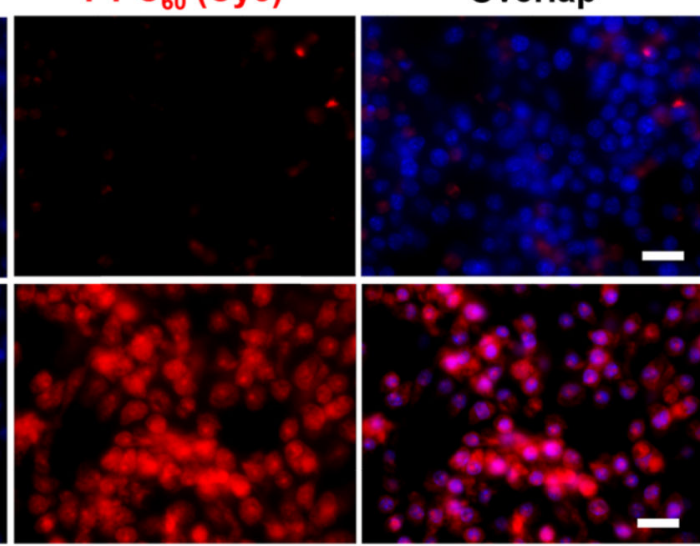

d

e

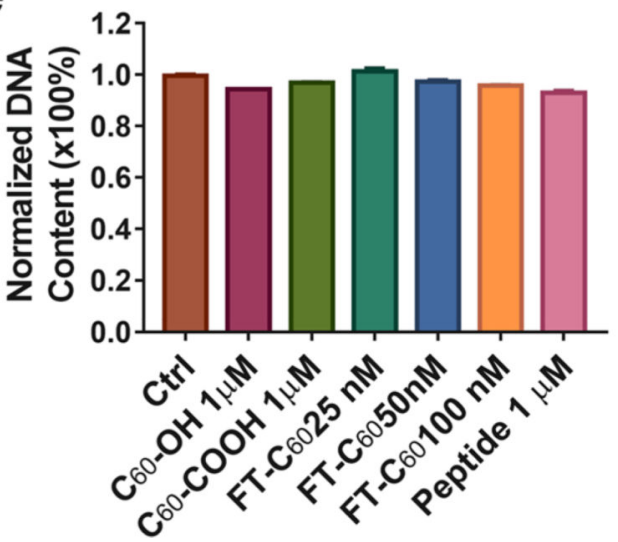

f

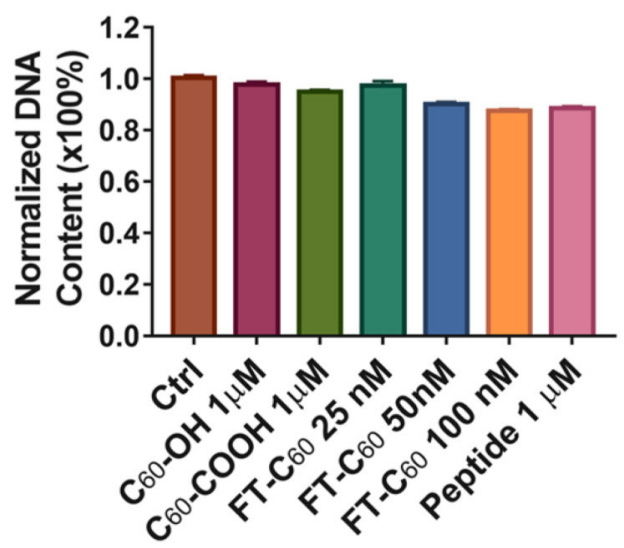

Figure 5.

FT- $\mathrm{C}_{60}$ showed preferential binding toward LPS stimulated macrophages with negligible cytotoxicity in vitro. Representative fluorescence images suggested both peptide $\mathbf{1}$ at $1 \mu \mathrm{M}$ (a) and $\mathrm{FT}^{-\mathrm{C}_{60}}$ at $100 \mathrm{nM}$ (c) demonstrated preferential binding properties to FPR-1 on LPSstimulated macrophages compared to non-LPS treated controls. Quantitative analysis of mean cellular fluorescence intensities of peptide $\mathbf{1}(\mathrm{b})$ and $\mathrm{FT}^{-\mathrm{C}_{60}}$ (d) groups confirmed binding to activated macrophages over nontreated control cells (****p $p<0.0001, t$ test). In addition, FT- $_{60}$ exhibited negligible cytotoxicity in macrophages after in vitro culture for 1 
day (e) and 3 days (f). Note that, for panels (a) and (c), the scale bar was $20 \mu \mathrm{m}$. Images were taken at a magnification of $600 \times$ using Cy5 and DAPI channels. For panels (b) and (d), 50 cells were analyzed per group. 

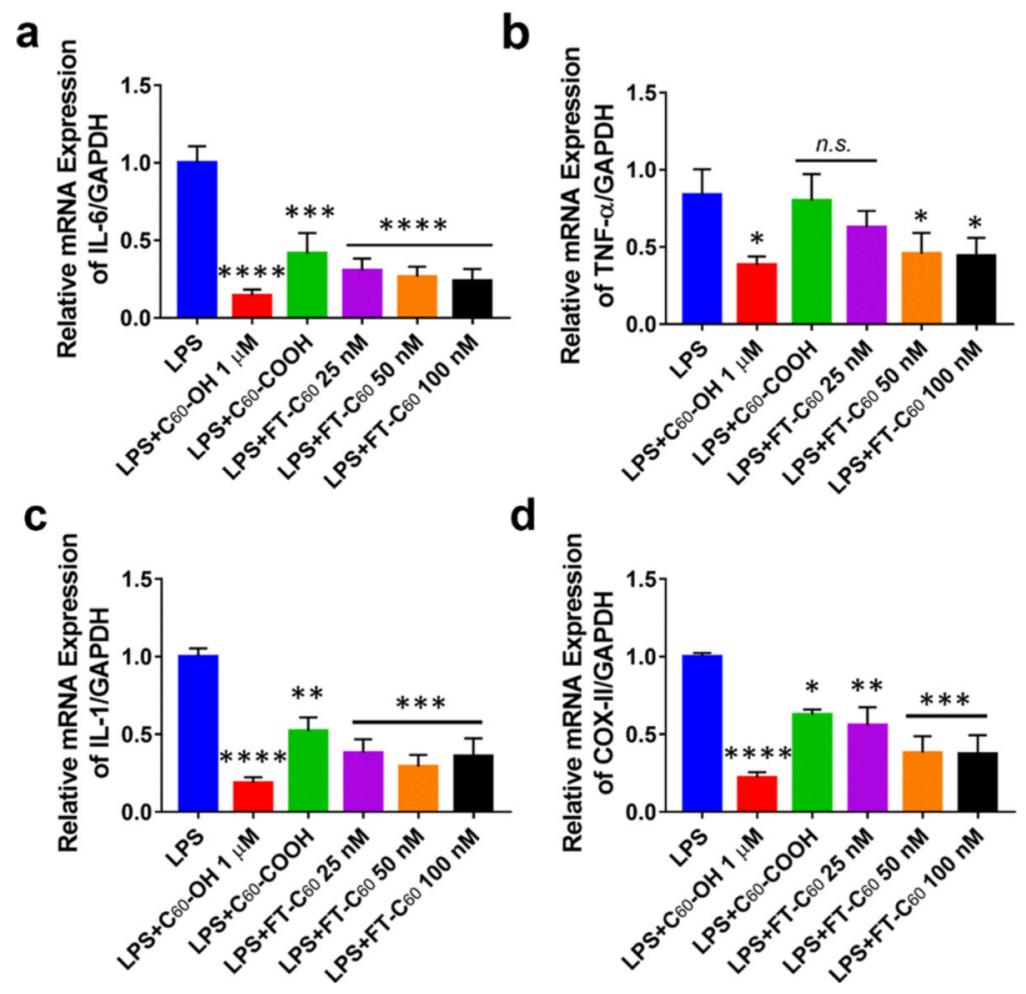

Figure 6.

FT- $\mathrm{C}_{60}$ effectively inhibited LPS-induced mRNA expression of proinflammatory cytokines in cultured macrophages. FT- $\mathrm{C}_{60}$ suppressed the mRNA expressions of (a) IL-6, (b) TNF- $a$, (c) IL-1, and (d) COX-II elicited by LPS. These protective, anti-inflammatory effects were also seen in fullerol $\left(\mathrm{C}_{60}-\mathrm{OH}\right)$ and functionalized fullerene $\left(\mathrm{C}_{60}-\mathrm{COOH}\right)$. Raw 264.7 macrophages were treated with LPS $(100 \mathrm{ng} / \mathrm{mL})$ overnight. GAPDH was used as a housekeeping gene to normalize the gene of interest. One-way ANOVA with multiple comparisons was used for data analyses. ${ }^{*} p<0.05, * * p<0.01, * * * p<0.001, * * * *<$ 0.0001 vs LPS treated groups. n.s. indicated not significant different between two groups. 

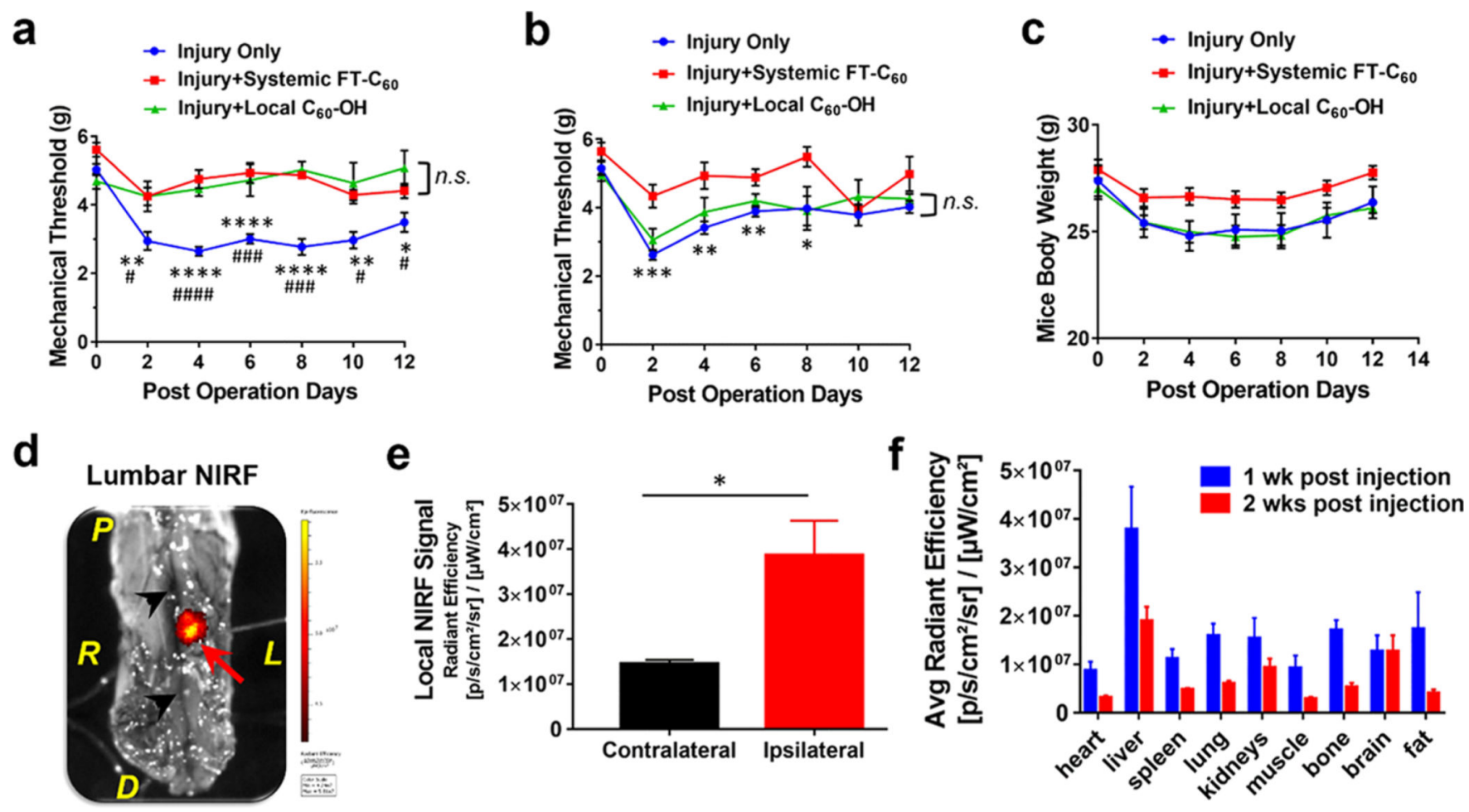

Figure 7.

Systemic delivery of newly developed targeted nanoparticle $\left(\mathrm{FT}_{-} \mathrm{C}_{60}\right)$ effectively attenuated pain in a mouse model of lumbar radiculopathy secondary to disc herniation. (a) Single injection (iv) of FT-C 60 (10 nmol per $20 \mathrm{~g}$ mice $)$ effectively attenuated mechanical hyperalgesia in a mouse model of lumbar radiculopathy up to POD 12, similar to intraoperative local administration of fullerol $\mathrm{C}_{60}(1 \mu \mathrm{M}, 10 \mu \mathrm{L})$. (b) Neither injury nor injury + treatment (systemic and local) groups showed significantly altered contralateral mechanical threshold. (c) Animal body weights of injury groups w/or w/o fullerol $\mathrm{C}_{60}$ treatment showed a slight decline first (POD 0-8) and then an upward recovery, whereas the FT- $_{60}$ treated group maintained a relatively stable trend over time. (d) Ex vivo near infrared fluorescence imaging (NIRF) of the mouse spine depicted the targeting property of FT- $\mathrm{C}_{60}$ toward inflammatory cells of injured discs on POD 7 (7 days after tail vein injection as well), evidenced by signal registration with the microscopically confirmed disc puncture site (red arrow). P, proximal; D, distal; L, left (ipsilateral); R, right (contralateral); Black arrowheads, midplane of spine. (e) Semiquantitative analysis of the localized NIRF signal supported the significantly higher ( $\sim$-fold) NIRF signal (targeted FT-C 60 accumulation) near the ipsilateral puncture site, compared to the contralateral side $(* p<0.05)$. (f) Semiquantitative organ distribution profile of $\mathrm{FT}_{-} \mathrm{C}_{60}$ after intravenous administration for 1 week and 2 weeks using IVIS fluorescence imaging illustrated dynamic hepatobiliary clearance of systemic delivered FT-C 60 . Note: One-way ANOVA with multiple comparisons and multiple t tests were used in panels (a) and (b). For injury only group, $* p<0.05, * * p<$ $0.01, * * * p<0.001, * * * * p<0.0001$ vs Injury + Systemic FT-C 60 , and ${ }^{\#} p<0.05,{ }^{\#} p<0.01$,

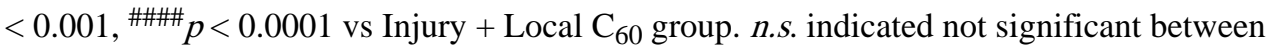
two groups. 
a

Injury

Injury+FT- $\mathrm{C}_{60}$

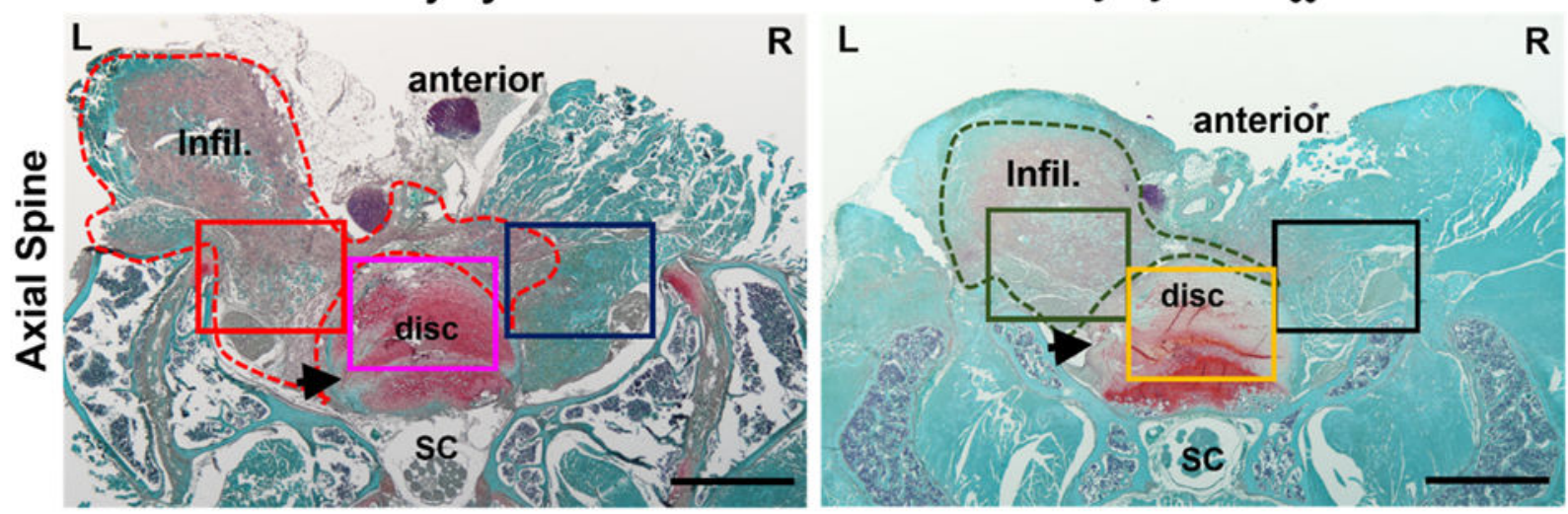

b
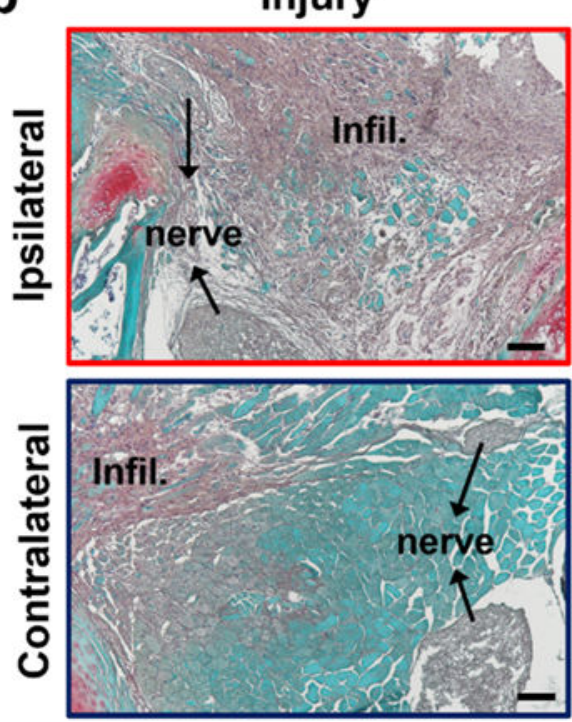

e

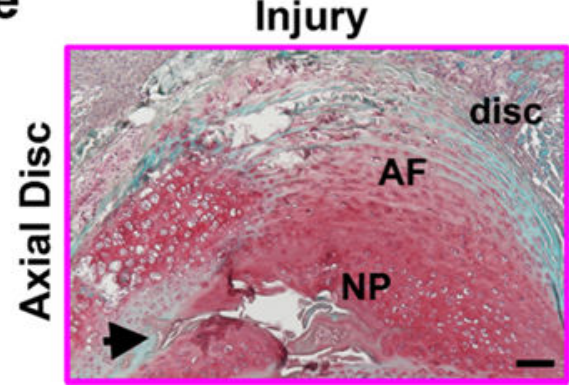

Injury+FT- $\mathrm{C}_{60}$
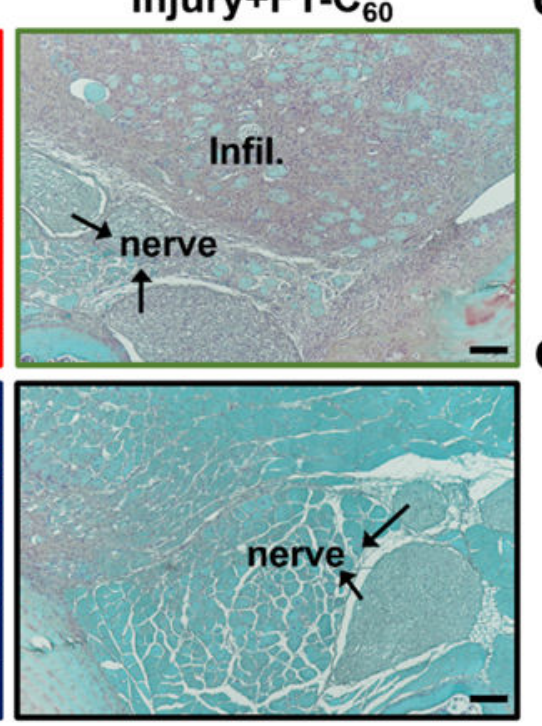

Injury+FT- $C_{60}$

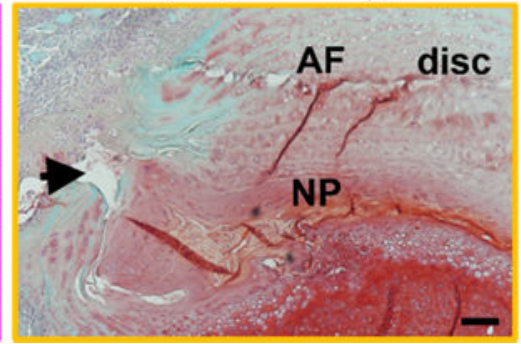

C
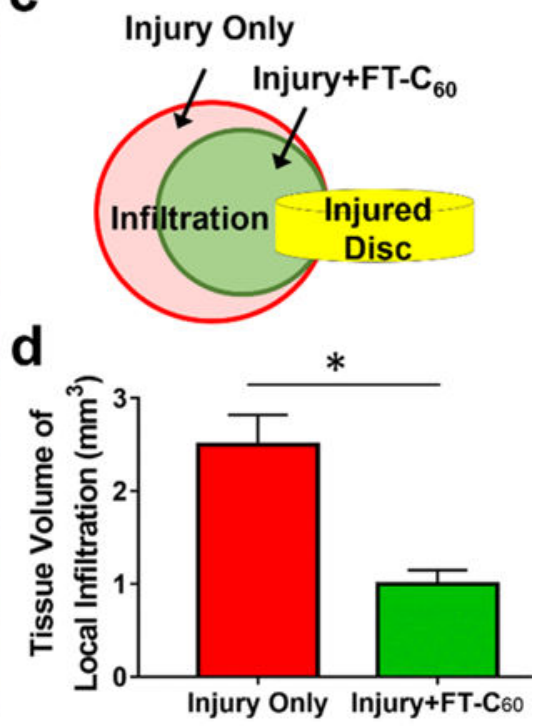

Intact

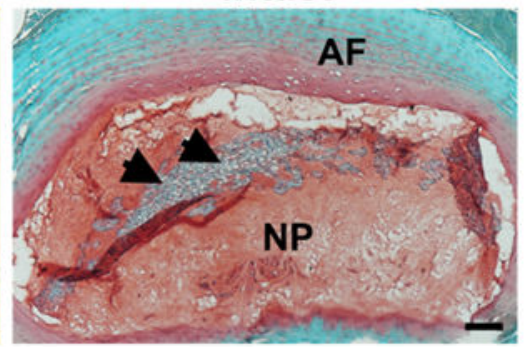

Figure 8.

Histological analysis (safranin-O/fast green staining) indicated decreased infiltration tissue volume near the disc puncture site on POD 7. (a) Low (40x)-and (b) high (200x)magnification axial spine images in the injury group w/ and w/o FT-C 60 (10 nmol per $20 \mathrm{~g}$ mice, iv) exhibited degenerative disc and abundant inflammatory cells at injury sites close to the exposed nerve root. (c,d) Customized quantitative analysis of infiltration tissue exhibited that systemic FT- $\mathrm{C}_{60}$ reduced the calculated volume of inflammatory tissue. (e) Axial discs in injured groups showed typical signs of degeneration with trajectory of disrupted AF. Infil, 
inflammatory infiltration; SC, spinal cord; nerve, spinal nerve; AF, annulus fibrosus; NP, nucleus pulposus. (a) Scale bar $=500 \mu \mathrm{m}$. (b,e) Scale bar $=100 \mu \mathrm{m}$. 